\title{
A Template for Defining Enterprise Modelling Constructs
}

\author{
Andreas L. Opdahl, University of Bergen, Norway \\ Brian Henderson-Sellers, University of Technology, Sydney, Australia
}

\begin{abstract}
The paper explains the need for a standard way of defining modelling constructs from different enterprise modelling languages and proposes a template for defining enterprise modelling constructs in a way that facilitates language integration. The template is based on the Bunge-Wand-Weber (BWW) representation model of information systems (IS) and has been used on several existing modelling languages and frameworks. It is illustrated with definitions of constructs from the Unified Modeling Language (UML). The paper focusses on modelling constructs that represent concrete problem domains, i.e., that represent materials rather than concepts, and thus focuses on the concrete parts and aspects of enterprises.
\end{abstract}

Keywords: problem domain representation; object-oriented analysis; ontological analysis and evaluation; Bunge-Wand-Weber (BWW) model; Unified Modeling Language; UML

\section{BACKGROUND}

Modelling languages and ontologies for enterprises and their information systems (IS) are becoming increasingly important. New and emerging technologies, such as enterprise application integration, enterprise content management, domainspecific languages, intelligent agents and the semantic web, all rely on models of or ontologies for enterprises. As more and more enterprise knowledge is captured in models, there is a danger that the knowledge is dispersed into many small ,isolated islands because it is represented in a variety of different modelling languages. Language standardisation alone is not sufficient to solve this problem because different modelling domains, modelling problems, user communities, business partners and model-based tools will require their own dedicated modelling languages in the future as they do today. 
To ensure that knowledge captured in enterprise models can be integrated and made available throughout the organisation, it is therefore necessary to enable organisations to integrate more closely the different modelling languages they use.

Philosophical ontology offers a common ground for integrating enterprise and IS modelling languages. According to Weber (1997), philosophical ontology is the branch of philosophy that deals with theories about the nature of things in general, as opposed to theories about particular things. In the IS field, one much used philosophical ontology is the Bunge-WandWeber (BWW) model of information systems (e.g., Wand \& Weber, 1988, 1993, 1995), which adapts Mario Bunge's (1977, 1979) comprehensive ontology to the IS field. Bunge's ontology is an example of scientific r ealism, meaning that it "identifies reality with the collection of all concrete things, [...] postulates the autonomous existence of the external world, admits that we are largely ignorant of it, and encourages us to explore it" (Bunge, 1999). It is therefore well suited for integrating modelling constructs that represent concrete problem domains, i.e., that represent materials rather than concepts. The BWW model is a set of three models, of which this paper will only use one: the representation model.

This paper uses the BWW representation model-called just the BWW model in this paper-as a common ground for defining enterprise and IS modelling constructs in a way that facilitates language integration. The paper thereby focusses on the concrete parts and aspects of enterprises, and proposes a template for defining enterprise and IS modelling constructs. By "template" we mean a standard way of defining modelling constructs by filling in standard set of "entries", some of which are complex and some of which are interrelated. Figures 16 will introduce the template stepwise in a series of UML class diagrams. The main idea is to provide a standard way of defining modelling constructs in terms of the BWW model, in order to make the definitions cohesive and, thus, learnable, understandable and as directly comparable to one another as possible. Another important idea is to provide a way of defining modelling constructs not only generally, in terms of whether they represent "classes", "properties" or other ontological categories, but also in terms of which classes and/or properties they represent, in order to make the definitions more clearly and precisely related to the enterprise. Although most of the paper is about the concrete parts and aspects of enterprises, we believe the template and other results of this paper are sufficiently general to apply to concrete problem domains in general.

The template has been developed based on practical experience from analysing, suggesting improvements to and providing precise definitions of several fullscale integrated modelling languages and frameworks, including:

- 73 constructs from the OPEN Modeling Language (OML) (Firesmith, Henderson-Sellers \& Graham, 1997) in Opdahl, Henderson-Sellers \& Barbier, 1999; Opdahl \& Henderson-Sellers (2001) and

- 68 constructs from the Unified Modeling Language (UML) (OMG, 2001) in Opdahl \& Henderson-Sellers (2002).

The template will be illustrated with definitions of constructs from the UML Version 1.4. Next, we will explain the underlying theory of the paper-the BWW 
model-and then introduce the template itself, before we present results of using the template to define constructs from the UML. This is followed by a discussion of the usefulness of the template, and conclusions and paths for further work. The outcome is threefold. Firstly, the template offers a standard way of precisely defining modelling constructs and thereby integrating different modelling languages. Secondly, the template makes the BWW model more easy to use for integrating modelling languages. Thirdly, the illustration of the template with definitions of constructs from the UML is a contribution to making the UML more precisely defined.

The template was preliminarily outlined by Opdahl, Henderson-Sellers and Barbier (1999), and is presented in an extended and much refined form here.

\section{THEORY}

The Bunge-Wand-Weber representation model (e.g., Wand \& Weber, 1988, 1993, 1995) — called the BWW model in this paper-has already been used to analyse and evaluate the modelling constructs of many established IS and enterprise modelling languages, including:

- dataflow diagrams (Wand \& Weber, 1989),

- ER models (Wand \& Weber, 1989; Weber, 1997),

- NIAM (Weber \& Zhang, 1996),

- nine languages supported by the Upper CASE-toolset Excelerator (Green, 1996),

- four languages supported by the ARIS toolset for business modelling (Green \& Rosemann, 1999, 2000),

- the OPEN Modelling Language (OML) (Opdahl \& Henderson-Sellers, 2001) and

- the Unified Modelling Language (UML) (Evermann \& Wand, 2001; Opdahl \& Henderson-Sellers, 2002). The BWW model has also been used for general analyses of :

- IS design theory (Wand, 1989a),

- object-oriented modelling constructs (Wand, 1989b; Parsons \& Wand, 1997),

- systems decomposition (Wand \& Weber, 1990; Paulson \& Wand, 1992),

- object-oriented information systems (Takagaki \& Wand, 1991),

- dimensions of data quality (Wand \& Wang, 1996),

- optional properties in conceptual modelling (Bodart et al., 2001),

- a two-layered information modelling approach where instances are not tied to particular classes (Parsons \& Wand, 2000) and

- whole-part relationships (like UML's aggregation and composition constructs) in OO models (Barbier et al., 2000; Opdahl, Henderson-Sellers \& Barbier, 2001).

The BWW model is therefore a natural starting point for a template for defining enterprise modelling constructs, although alternatives exist both in the form of general philosophical ontologies, e.g., Chisholm (1996), or special enterprise and IS ontologies, e.g., the enterprise ontology (Uschold et al., 1998) and the framework of information systems concepts (FRISCO) (Verrijn-Stuart et al., 2001). In support of the BWW model, Wand \& Weber (1993) have argued that Bunge's ontology is:

1. better developed and formalised than alternative philosophical ontologies;

2 . based on concepts that are fundamental 
to the computer science and information systems domains; and

3. productive, in the sense that it has given useful results.

Space does not permit a full presentation of the BWW model, but this section will present the most important BWW concepts that we will use. Table 1 gives definitions of all the BWW concepts used in the paper.

Things and Properties: According to Bunge's ontology and the BWW model, there is a world that exists independently of human observers, and it consists of things that possess properties. Examples of BWW-things are "atoms, fields, persons, artifacts and social systems" (Bunge, 1999), whereas "properties of things (e.g., energy) changes in them, and ideas considered in themselves" are non-things (Bunge, 1999). In particular, concepts are not BWW-things.

Bunge's ontology and the BWW model also reminds us that we only know about things via models of things we create in our minds, and that we ascribe attributes to those models of things to stand for the properties we believe the corresponding things possess. In the BWW model, an attribute (that stands for a BWW-property) is represented as a property function of time, which maps the property onto different property values in a property co-domain for different points in time.

Properties: The BWW model distinguishes between properties in several different ways. An intrinsic property belongs to only a single thing, whereas a mutual property belongs to two or more things. (BWW-mutual properties are represented by relationships or similar constructs in many modelling languages.) A whole-part relation is a property that relates an aggregate thing to one of its component things. A resultant property belongs to a BWW-aggregate and is derived from one or more properties of its components, whereas an emergent property belongs to a BWW-aggregate but not to any of its components. A law property restricts other properties of the same thing. A BWW-law is either a state law or a transition law. An individual property (or property of a particular) is a specific, e.g., "being 25 years old" and "having grey hair," whereas the corresponding general properties are "having an age" and "having a hair color." Bunge (1977) also distinguishes between BWW-properties that are permanent and those that are variable.

BWW-properties may be complex, i.e., they may have other properties as constituents. A BWW-property precedes a second BWW-property if and only if:

- either (a) the second property is complex (or compound) and the first property is one of its constituents,

- or (b) a BWW-law states that all BWW-things that possess the second property must also possess the first.

According to (a), "having a ZIPcode" precedes "having a postal address" because every postal address includes a ZIP-code and, according to (b), "being a human being" precedes "being married,"

Classes: Things with a property in common form $B W W$-classes. A class contains all the things, and only those things, that possess one or more characteristic properties for the class. In other words, every BWW-class is defined by a nonempty set of characteristic properties of the things in the class. The most general BWW-class is the class off all things, which is defined by the universal property of being able to associate with other 
things (Bunge, 1977). Because characteristic properties may be complex, it is sometimes possible to say that a BWWclass is defined by a group of characteristic BWW-properties. One BWW-class may be defined by a group of characteristic properties that is contained in a larger group of properties that defines a second class. We then say that the second BWW-class is a subclass of the first.

Coupling and Systems: A BWWthing has time-dependent states that are determined by the values of the thing's property functions over time. A change of BWW-state in a thing is an event, hence a BWW-event can be described as a pair of BWW-states. Consecutive BWW-events form complex events, or processes if they occur in the same thing. The sequence of consecutive BWW-states undergone by a thing (or, alternatively, the sequence of consecutive BWW-events) is called its history. A BWW-thing acts on a second thing if and only if the BWW-history of the second thing would have been different had the first thing not existed. The first thing is called an active thing. Two BWW-things are coupled if and only if (at least) one of them acts on the other. BWW-couplings are caused by certain BWW-mutual properties that are said to be binding. A BWW-aggregate whose BWWcomponents are coupled is a system.

\section{THE TEMPLATE}

\section{Overview}

The template is used to define each modelling construct separately by filling in four types of top-level entries, some of which have sub-entries:

- The instantiation level entry type is used to define whether the modelling construct represents the enterprise at the type level, at the instance level or at either level. This is the simplest type of top-level entry.

- The class entry type is used to define which class of things (or classes of things) in the enterprise that the modelling construct may represent. We will see later that a modelling construct may be defined by multiple class entries, each of them with several sub-entries.

- The property entry type is used to define which property (or properties) in the enterprise the construct may represent. We will see that it too may be repeated and may have several subentries.

- The lifetime entry type is used to define whether the modelling construct represents events in, states of, processes in or the whole lifetime of one or more things.

We will now discuss each type of top-level entry separately using constructs from the UML - and sometimes from other languages - as examples. Although the UML is not primarily an enterprise or IS modelling language, it is relevant here because it is often used to represent concrete problem domains in the early stages of systems development. It is also a natural example language because it is widely known.

\section{Instantiation Level}

The first and simplest entry type is used to define the instantiation level of a modelling construct. The construct is at the type level if it represents BWW-classes (or their characteristic properties, etc.) and it is at the instance level if it represents BWW-things (and/or their properties, 
Table 1: Basic concepts in the BWW model

\begin{tabular}{|c|c|}
\hline$\frac{\text { BWW concept }}{\text { BWW-thing }}$ & $\begin{array}{l}\text { Concept definition } \\
\text { "The elementary unit in our ontological model. The real } \\
\text { world is made up of things." (Wand \& Weber, 1995) }\end{array}$ \\
\hline BWW-property of a thing & $\begin{array}{l}\text { "Things possess properties" (Wand \& Weber, 1995). "We } \\
\text { know about things in the world via their properties" (Weber, } \\
\text { 1997). }\end{array}$ \\
\hline BWW-complex property & $\begin{array}{l}\text { A complex BWW-property consists of other properties, } \\
\text { which may themselves be complex. }\end{array}$ \\
\hline BWW-property function & $\begin{array}{l}\text { "A property is modeled via a function that maps the thing } \\
\text { into some value" (Wand \& Weber, 1995). A BWW-property } \\
\text { function represents how some BWW-property changes over } \\
\text { time. BWW-property functions are also called state functions } \\
\text { (Weber, 1997) or state variables (Parsons \& Wand, 1997). }\end{array}$ \\
\hline BWW-property co-domain & $\begin{array}{l}\text { "The set of values into which the function that stands for the } \\
\text { property of a thing maps the thing" (Weber \& Zhang, 1996). }\end{array}$ \\
\hline BWW-class of things & $\begin{array}{l}\text { "A set of things that can be defined by their possessing a } \\
\text { particular set of properties" (Weber \& Zhang, 1996). 1) A } \\
\text { BWW-class is defined by a "characteristic set" of properties. } \\
\text { 2) All groups of BWW-properties that are possessed by at } \\
\text { least one BWW-thing define a BWW-class. }\end{array}$ \\
\hline $\begin{array}{l}\text { BWW-subclass of things } \\
\text { two or more things }\end{array}$ & $\begin{array}{l}\text { "A set of things that can be defined via their possessing the } \\
\text { set of properties in a class plus an additional set of } \\
\text { properties" (Weber \& Zhang, 1996). (Hence, a BWW- } \\
\text { subclass is itself a BWW-class.) }\end{array}$ \\
\hline BWW-intrinsic property of a thing & $\begin{array}{l}\text { "A property that is inherently a property of an individual } \\
\text { thing" (Wand \& Weber, 1995). }\end{array}$ \\
\hline BWW-mutual property of & $\begin{array}{l}\text { "A property that is meaningful only in the context of two or } \\
\text { more things" (Wand \& Weber, 1995). }\end{array}$ \\
\hline BWW-state of a thing & $\begin{array}{l}\text { "The vector of values for all property functions of a thing" } \\
\text { (Wand \& Weber, 1995). }\end{array}$ \\
\hline BWW-state law of a thing & $\begin{array}{l}\text { A property that "[r]estricts the values of the property } \\
\text { functions of a thing to a subset that is deemed lawful because } \\
\text { of natural laws or human laws" (Wand \& Weber, 1995). }\end{array}$ \\
\hline
\end{tabular}


Table 1, Continued: Basic concepts in the BWW model

\begin{tabular}{|c|c|}
\hline BWW-event in a thing & $\begin{array}{l}\text { "A change of state of a thing. It is affected via a } \\
\text { transformation (see below)" (Wand \& Weber, 1995). }\end{array}$ \\
\hline BWW-process in a thing & $\begin{array}{l}\text { "An intrinsically ordered sequence of events on, or states } \\
\text { of, a thing" (Green, 1996). Processes may be either chains } \\
\text { or trees of events (Bunge, 1977). }\end{array}$ \\
\hline BWW-transformation of a thing & $\begin{array}{l}\text { "A mapping from a domain comprising states to a co- } \\
\text { domain comprising states" (Wand \& Weber, 1995). }\end{array}$ \\
\hline $\begin{array}{l}\text { BWW-transformation } \\
\text { law of a thing }\end{array}$ & $\begin{array}{l}\text { "Events are governed by transformation laws that define } \\
\text { the allowed changes of state" (Parsons \& Wand, 1997). } \\
\text { (Wand \& Weber, 1995) and other papers on the BWW } \\
\text { model instead introduce } B W W \text {-lawful transformations, } \\
\text { which define "which events in a thing that are lawful". The } \\
\text { term "transformation law" instead of "lawful } \\
\text { transformation" is chosen here to emphasise that a } \\
\text { transformation law - like a state law - is a property of a } \\
\text { particular thing. }\end{array}$ \\
\hline BWW-law property of a thing & $\begin{array}{l}\text { "Properties can be restricted by laws relating to one or } \\
\text { several properties" (Parsons \& Wand, 1997). 1) A law is } \\
\text { either a state law or a transformation law of a particular } \\
\text { thing. 2) A law is either a natural law or a human law (see } \\
\text { below.) }\end{array}$ \\
\hline BWW-natural law & $\begin{array}{l}\text { "Natural laws are established by nature" (Weber, 1997). } \\
\text { For example, a law of physics. }\end{array}$ \\
\hline BWW-human law & $\begin{array}{l}\text { "Some laws are human-made artifacts" (Weber, 1997), i.e., } \\
\text { they are socially constructed and enforced by humans. } \\
\text { Events and processes may sometimes violate human laws, } \\
\text { but not natural ones. }\end{array}$ \\
\hline BWW-natural kind of things & $\begin{array}{l}\text { "A natural kind is defined by a set of properties and the } \\
\text { laws connecting them" (Parsons \& Wand, 1997). 1) Hence, } \\
\text { a BWW-natural kind is itself a BWW-class, but all its } \\
\text { characteristic properties must be BWW-laws. 2) In this } \\
\text { paper, we refer to the "subclasses" of BWW-natural kinds } \\
\text { as } B W W-\text {-sub-kinds. }\end{array}$ \\
\hline BWW-conceivable state & $\begin{array}{l}\text { "The set of all states that the thing may ever assume" } \\
\text { (Wand \& Weber, 1995). }\end{array}$ \\
\hline $\begin{array}{l}\text { BWW-possible state } \\
\text { space of a thing }\end{array}$ & $\begin{array}{l}\text { "[T] he space of states that are possible given our } \\
\text { understanding of the laws of nature" (Weber, 1997). }\end{array}$ \\
\hline $\begin{array}{l}\text { BWW-lawful state space of a thing } \\
\text { space of a thing }\end{array}$ & $\begin{array}{l}\text { "[T]he set of states of a thing that comply with the state } \\
\text { laws of the thing" (Wand \& Weber, 1995). Hence, lawful } \\
\text { states satisfy both human and natural state laws, whereas } \\
\text { possible states may violate human ones. }\end{array}$ \\
\hline $\begin{array}{l}\text { BWW-conceivable event } \\
\text { space of a thing }\end{array}$ & $\begin{array}{l}\text { "The set of all possible events that can occur in the thing" } \\
\text { (Weber \& Zhang, 1996). }\end{array}$ \\
\hline
\end{tabular}


Table 1, Continued: Basic concepts in the BWW model

\begin{tabular}{|c|c|}
\hline BWW-lawful event space of a thing & $\begin{array}{l}\text { "The set of all events in a thing that are lawful" (Wand \& } \\
\text { Weber, 1995). Weber (1997) adds "[...] because (a) nature } \\
\text { permits them to occur, and (b) there are no human laws that } \\
\text { denote them as unlawful". }\end{array}$ \\
\hline BWW-composite thing & $\begin{array}{l}\text { "A composite thing may be made up of other things } \\
\text { (composite or primitive)" (Wand \& Weber, 1995). "Things } \\
\text { can be combined to form a composite thing" (Parsons \& } \\
\text { Wand, 1997). }\end{array}$ \\
\hline BWW-component thing & $\begin{array}{l}\text { Any BWW-thing that is in the composition of a composite } \\
\text { thing. }\end{array}$ \\
\hline BWW-whole-part relation & $\begin{array}{l}\text { The property of being in the composition of another thing } \\
\text { or, complementary, of having another thing as a component } \\
\text { (according to Bunge, 1977)). }\end{array}$ \\
\hline $\begin{array}{l}\text { BWW-resultant property of a } \\
\text { composite thing }\end{array}$ & $\begin{array}{l}\text { "A property of a composite thing that belongs to a } \\
\text { component thing" (Wand \& Weber, 1995). }\end{array}$ \\
\hline $\begin{array}{l}\text { BWW-emergent property of a } \\
\text { composite thing }\end{array}$ & $\begin{array}{l}\text { A property of a composite thing that does not belong to a } \\
\text { component thing (adapted from (Wand \& Weber, 1995).) }\end{array}$ \\
\hline BWW-history of a thing & $\begin{array}{l}\text { "The chronologically ordered states that a thing traverses in } \\
\text { time" (Weber \& Zhang, 1996). }\end{array}$ \\
\hline $\begin{array}{l}\text { BWW-acting on another thing, } \\
\text { BWW-coupling of things }\end{array}$ & $\begin{array}{l}\text { "A thing acts on another thing if its existence affects the } \\
\text { history of the other thing. The two things are said to be } \\
\text { coupled [...]" (Wand \& Weber, 1995). }\end{array}$ \\
\hline $\begin{array}{l}\text { BWW-direct acting on, } \\
\text { BWW-binding mutual property }\end{array}$ & $\begin{array}{l}\text { A thing acts directly on one or more other things when the } \\
\text { former thing changes a } B W W \text {-binding mutual property they } \\
\text { all possess. Changing the binding mutual property is an } \\
\text { internal event in the former thing and an external event in } \\
\text { each of the latter things. }\end{array}$ \\
\hline BWW-system of things & $\begin{array}{l}\text { "A set of things is a system if, for any bi-partitioning of the } \\
\text { set, couplings exist among things in the two subsets" (Wand } \\
\& \text { Weber, 1995). 1) A BWW-system is itself a BWW-thing. } \\
\text { 2) BWW-system things belong to BWW-system natural } \\
\text { kinds. }\end{array}$ \\
\hline BWW-system composition & $\begin{array}{l}\text { "The things in the system" (Wand \& Weber, 1995), i.e., its } \\
\text { component things. }\end{array}$ \\
\hline BWW-system environment & $\begin{array}{l}\text { "Things that are not in the system but interact with things } \\
\text { in the system" (Wand \& Weber, 1995). }\end{array}$ \\
\hline BWW-system structure & $\begin{array}{l}\text { "The set of couplings that exist among things in the system } \\
\text { and things in the environment of the system" (Wand \& } \\
\text { Weber, 1995). }\end{array}$ \\
\hline BWW-subsystem & $\begin{array}{l}\text { "A system whose composition and structure are subsets of } \\
\text { the composition and structure of another system" (Wand \& } \\
\text { Weber, 1995). }\end{array}$ \\
\hline
\end{tabular}


Table 1, Continued: Basic concepts in the BWW model

\begin{tabular}{|c|c|}
\hline BWW-system decomposition & $\begin{array}{l}\text { "A set of subsystems such that every component in the } \\
\text { system is either one of the subsystems in the } \\
\text { decomposition or is included in the composition of one of } \\
\text { the subsystems in the decomposition" (Wand \& Weber, } \\
\text { 1995). }\end{array}$ \\
\hline BWW-level structure & $\begin{array}{l}\text { "Defines a partial order over the subsystems in a } \\
\text { decomposition to show which subsystems are } \\
\text { components of other subsystems or the system itself" } \\
\text { (Wand \& Weber, 1995). }\end{array}$ \\
\hline $\begin{array}{l}\text { BWW-external event in a thing, } \\
\text { subsystem or system }\end{array}$ & $\begin{array}{l}\text { "An event that arises in a thing, subsystem or system by } \\
\text { virtue of the action of some thing in the environment of } \\
\text { the thing, subsystem or system. The before-state of an } \\
\text { external event is always stable. The after-state may be } \\
\text { stable or unstable" (see below) (Wand \& Weber, 1995). 1) } \\
\text { Stable and unstable states will be defined below. 2) We } \\
\text { have not defined the subsystem-concept because we do } \\
\text { not need it in this paper. }\end{array}$ \\
\hline $\begin{array}{l}\text { BWW-internal event in a thing, } \\
\text { subsystem or system }\end{array}$ & $\begin{array}{l}\text { "An event that arises in a thing, subsystem or system by } \\
\text { virtue of lawful transformations in the thing, subsystem } \\
\text { or system. The before-state of an internal event is always } \\
\text { unstable. The after-state may be stable or unstable" (see } \\
\text { below) (Wand \& Weber, 1995). }\end{array}$ \\
\hline BWW-unstable state of a thing & $\begin{array}{l}\text { "A state that will be changed into another state by virtue } \\
\text { of the action of transformation in the system" (Wand \& } \\
\text { Weber, 1995). }\end{array}$ \\
\hline BWW-stable state of a thing & $\begin{array}{l}\text { "A state in which a thing, subsystem or system will remain } \\
\text { unless forced to change by virtue of the action of a thing } \\
\text { in the environment (an external event)" (Wand \& Weber, } \\
\text { 1995). }\end{array}$ \\
\hline
\end{tabular}

states, events, histories, etc.).

An obvious example is the distinction between UML-types at the type level and UML-objects at the instance level. ${ }^{1}$ (Table 2 will later show template-based definitions of all the modelling constructs from the UML that were considered in this paper. As can be seen from this table, the definitions of UML-objects and -types only differ in their instantiation level entries.)

Some constructs can even be used to represent either level. For example, processes in some dialects of traditional dataflow diagrams (DFDs) can represent either logical processes that can occur several places in an information system and are therefore at the type level - or physical processes that can occur only at a specific place - and therefore belong at the instance level.

Figure 1 shows the first part of a UML class diagram for the template, according to which a "ConstructDefinition" has a "constructName" and an "instLevel" as attributes. (In the UML, when multiplicities are not shown for attributes, the default is [1,1], so each “ConstructDefinition" has exactly one "instLevel" attribute. In this 
Figure 1: A UML class diagram of the instantiation level entr $y$.

\begin{tabular}{|l|}
\hline \multicolumn{1}{|c|}{ ConstructDefinition } \\
\hline ConstructName: String \\
inst Level : set_of $\{$ instance, type $\}$ \\
\hline
\end{tabular}

and later UML class diagrams, we allow attributes with set value types.)

\section{Class}

The second type of entry is used to define which class of things the modelling construct may represent. For a modelling construct at the type level, this means that the construct may only represent subclasses of the specified class. For a modelling construct at the instance level, this means that the construct may only represent things that belong to the specified class.

For example, at the type level, the UML has constructs that may only represent subclasses of the BWW-class of "ActiveThings", defined by the characteristic property of acting on other things. The UML also has constructs that may only represent subclasses of other important BWW-classes, such as the class of "ActedOnThings" or the class of "CompositeThings". (Figure 7 will later show a generalisation hierarchy of all the BWW-classes that are represented by modelling constructs from the UML.) Accordingly, at the instance level, the UML has constructs that may only represent active $\mathrm{BWW}$-things, other constructs that may only represent things that are acted on and still other constructs that may only represent composite things.

These restrictions are important parts of the semantics of the modelling constructs in question. The class entry type is particularly important for defining domainspecific languages, which are often organised as deep specialisation hierarchies. ${ }^{2}$ The entry type is also useful when comparing and analysing multiple models, because it makes it clear that some modelling constructs may never be used to represent the same classes or things in the problem domain.

Figure 2 extends the UML class diagram to show that a "ConstructDefinition" consists of one or more "RepresentedClasses", each of which is defined, according to the BWW model, by one or more "CharacteristicProperties".

According to Figure 2, the template allows repeated class entries for modelling constructs that may represent several different classes of things (at the type

Figure 2: The UML class diagram extended to show the class entry.

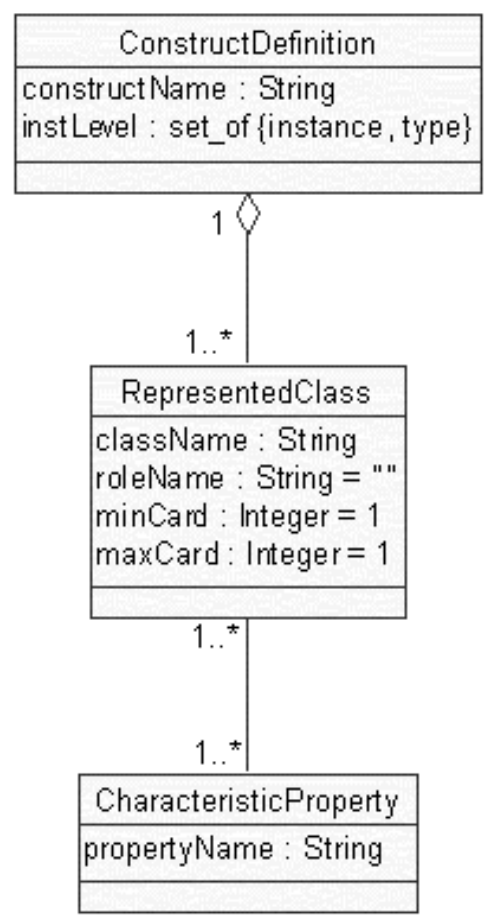


level) or several things of different classes (at the instance level). For example, for the moment, a UML-aggregation (at the type level) represents one "composite (or whole) class" and one "component (or part) class".

Whenever a construct definition has more than one class entry, they must be distinguished by "roleNames", as shown in Figure 2. UML-aggregation is therefore defined by two "RepresentedClasses", one with the "roleName" "whole" and one with the "roleName" "part". In this example, the two "RepresentedClasses" represent different $\mathrm{BWW}$-classes (because they have different “CharacteristicProperties"), but a construct definition may even have more than one "RepresentedClasses" for the same BWW-class as long as they have different "roleNames".

Even when the class entry is not repeated, a modelling construct may represent several subclasses of the same class in the same role (at the type level) or several things of the same class in the same role (at the instance level). In Figure 2, “RepresentedClass" therefore has minimum and maximum cardinalities, "minCard" and "maxCard", that default to 1. For example, a UML-link (at the instance level) represents two or more "AssociatedThings" and is therefore defined by a single "RepresentedClass", but one with "minCard"=2 (because the link connects at least two UML-objects) and "maxCard" $=-1$ (because -1 is used to indicate no upper limit on the number of objects.)

\section{Properties}

The third type of entry is used to define which properties of things the modelling construct may represent because, sometimes, different modelling constructs may represent the same class of things but not the same properties of those things. For example, in the UML the BWW-class of "ActiveThings" can be represented by UML-operations and UML-pre- and postconditions, but each UML construct nevertheless represents slightly different properties of active BWW-things. An additional example is found in Conallen's (1999) extension of the UML for developing web applications. His extension introduces several stereotypes of UMLassociations, one of them for representing web "hyperlinks", i.e., links that change the content of the web-browser frame that the links themselves are in, and another one for representing "target links", i.e., links that change the contents of other webbrowser frames. These two stereotypes have identical class entries because they both represent pairs of web pages, but they have different property entries because they represent different properties of those pairs.

Figure 3 extends the UML class diagram to show that a “ConstructDefinition” also consists of zero or more "RepresentedProperties", which specialise the "Properties" that characterise "RepresentedClasses". (In Figure 2, we have therefore changed the name of the "CharacteristicProperty" class to "Property" and instead added "characteristic" as a role of the "Property" class.) The template allows "ConstructDefinitions" with zero "RepresentedProperties" because there are modelling constructs that may not represent properties at all. For example, general constructs like UML-object and type do not have property entries because they do not themselves represent BWWproperties (although in the UML metamodel they are associated with other 


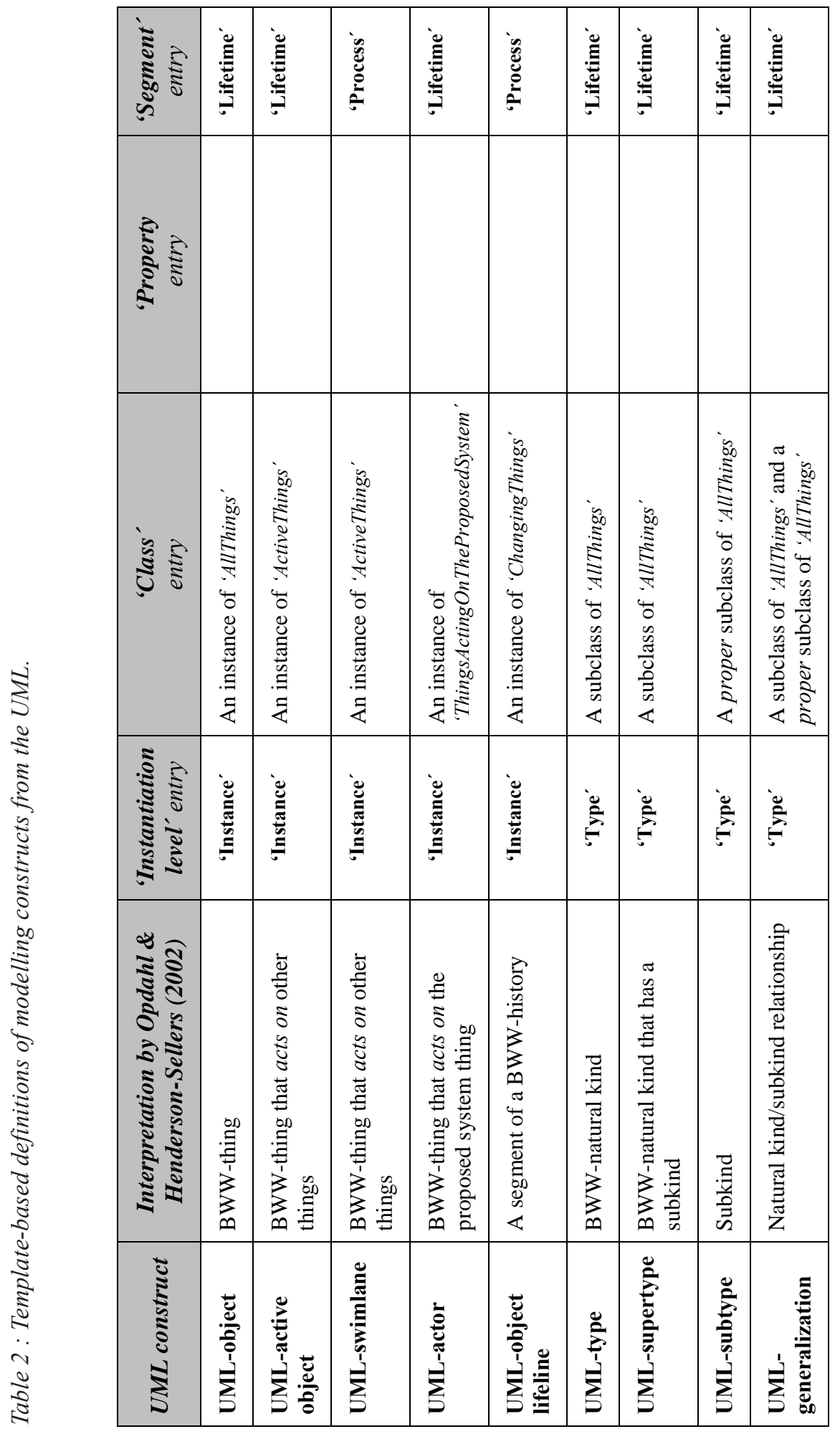




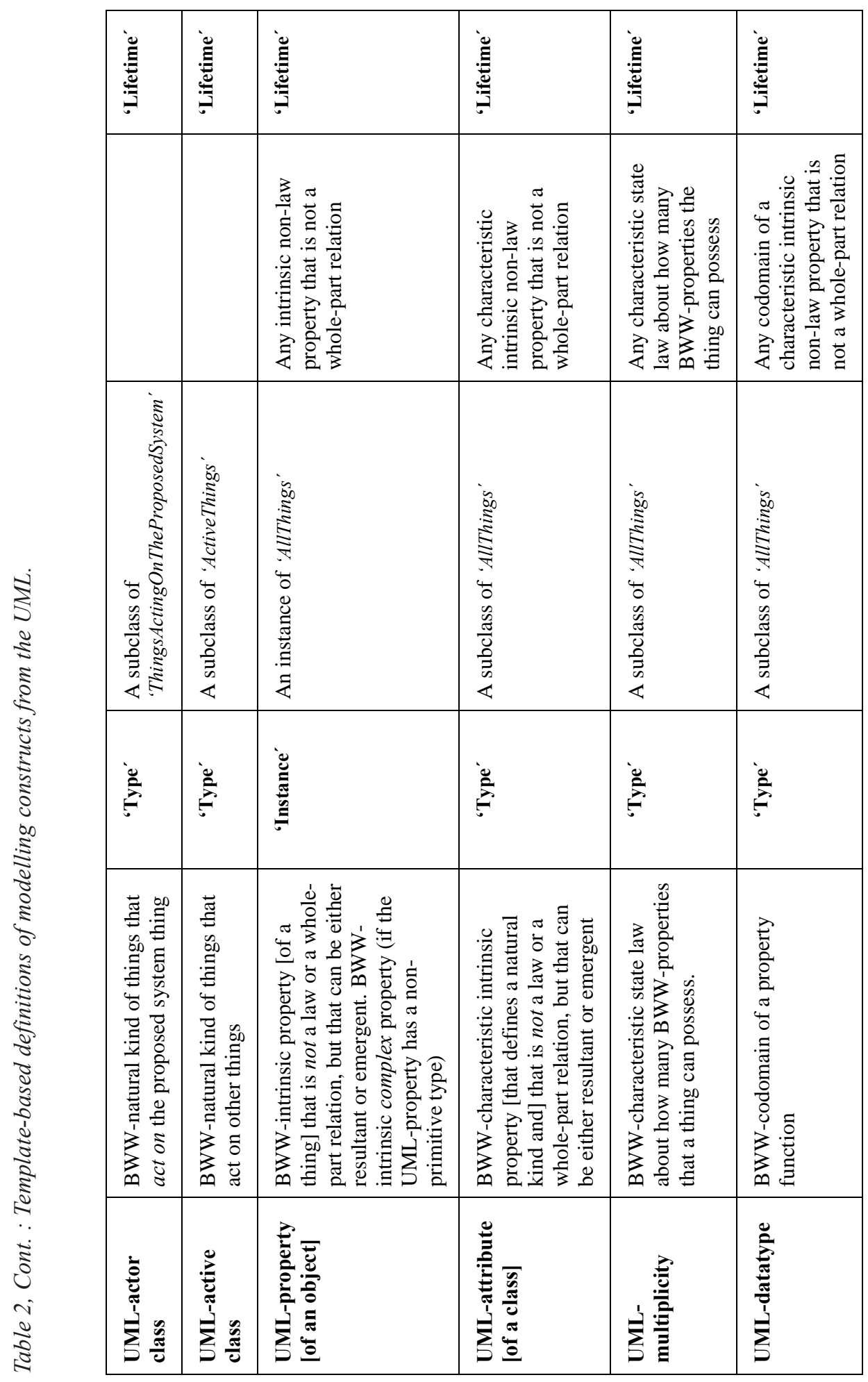




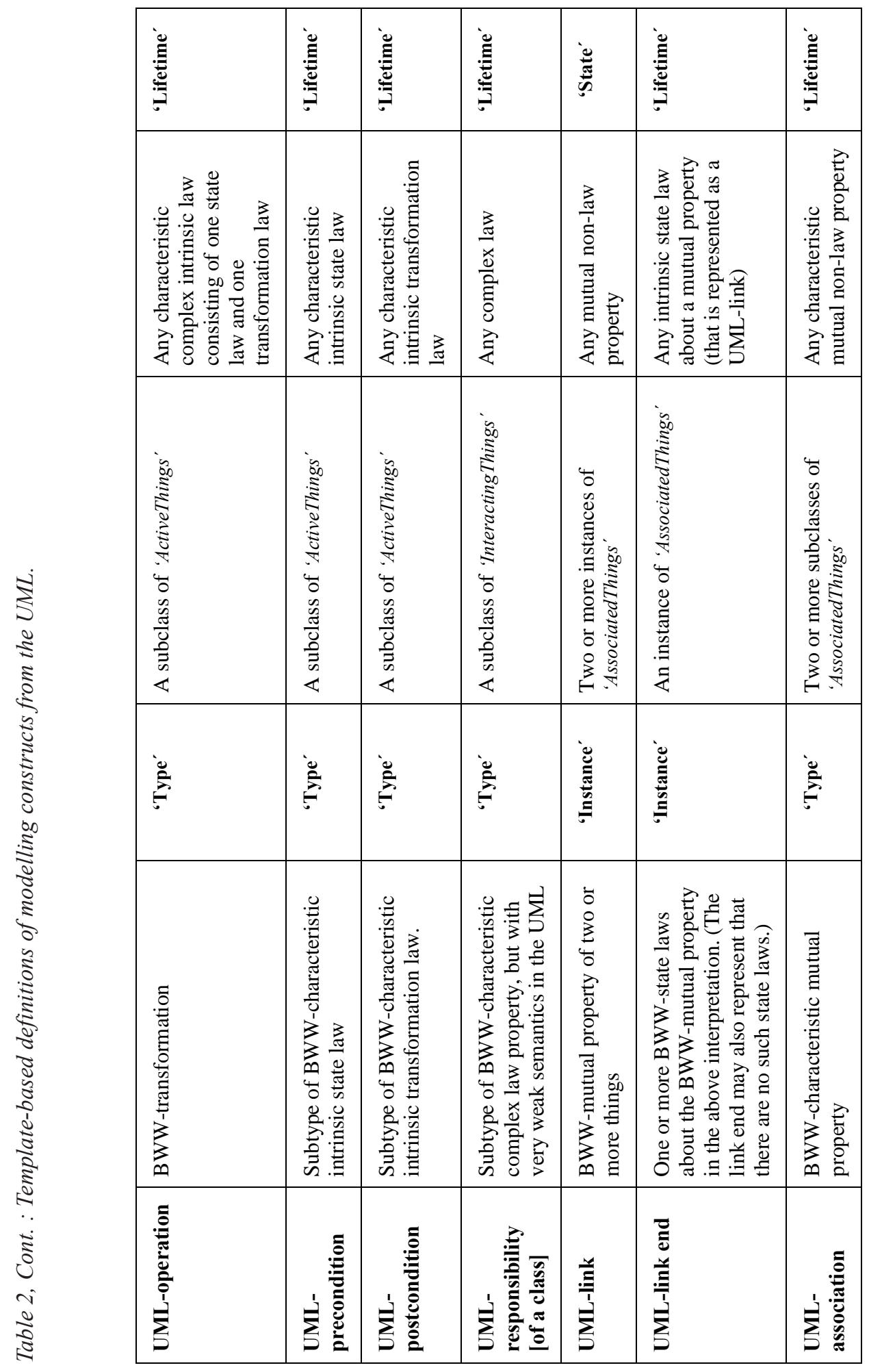




\begin{tabular}{|c|c|c|c|c|c|}
\hline 莺 & 号 & 莺 & 苛 & 岂 & 苛 \\
\hline 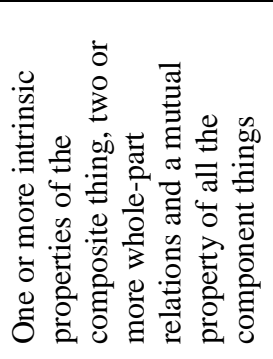 & 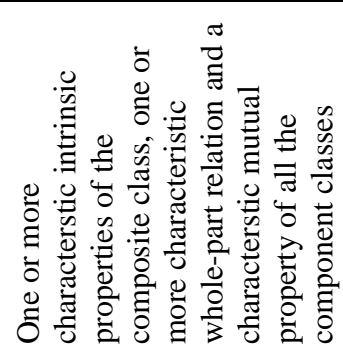 & 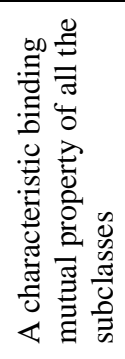 & 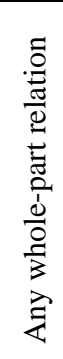 & 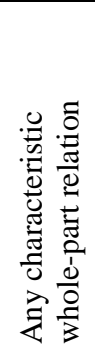 & 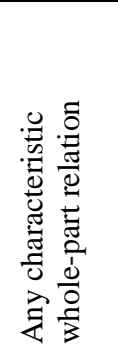 \\
\hline 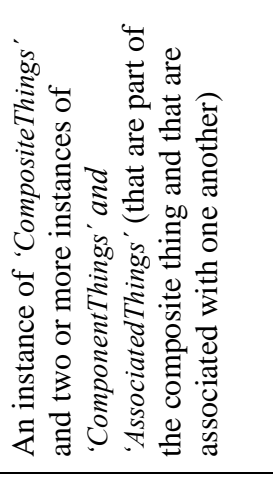 & 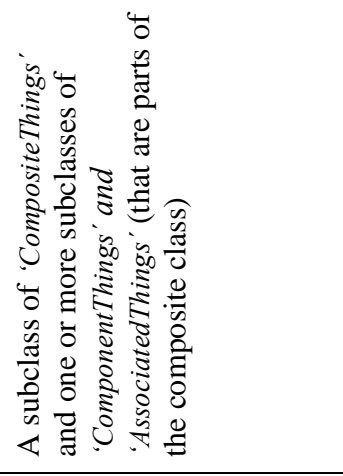 & 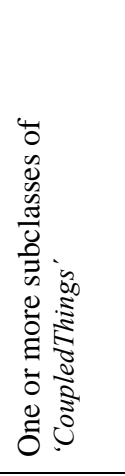 & 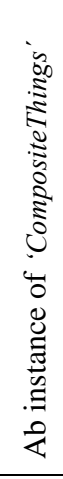 & 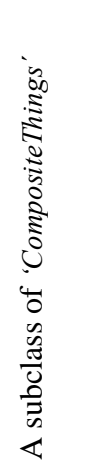 & 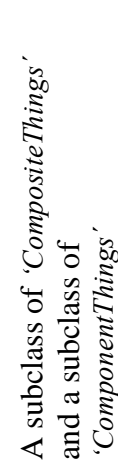 \\
\hline 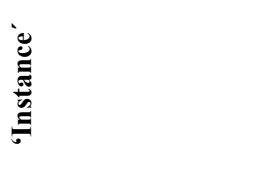 & ڤ్ర & לั. & 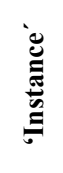 & है & है \\
\hline 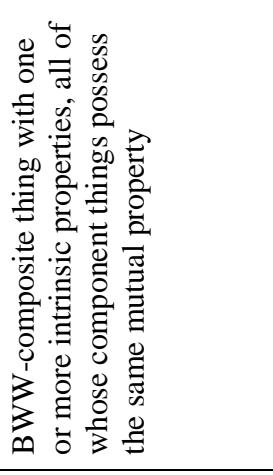 & 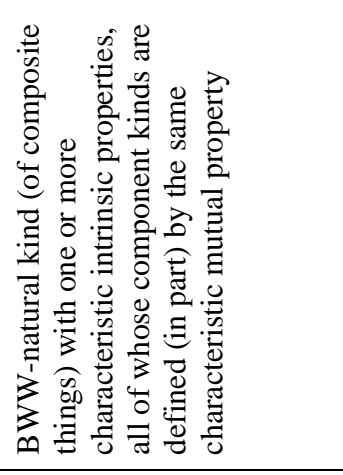 & 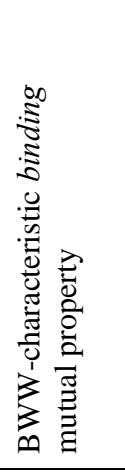 & 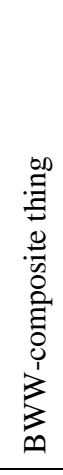 & 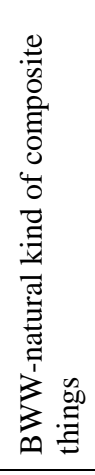 & 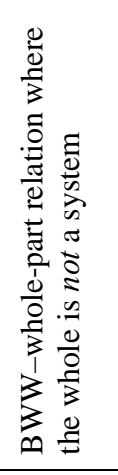 \\
\hline 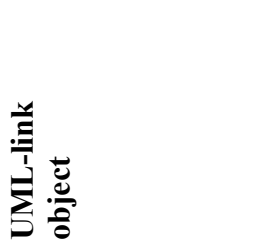 & 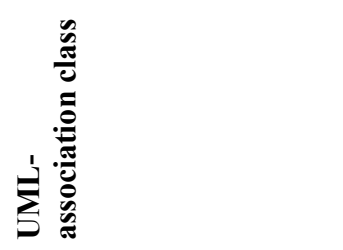 & 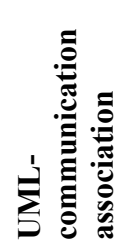 & 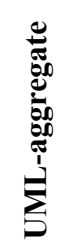 & 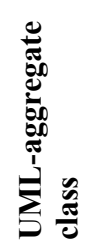 & 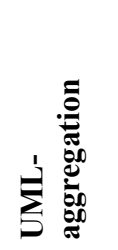 \\
\hline
\end{tabular}




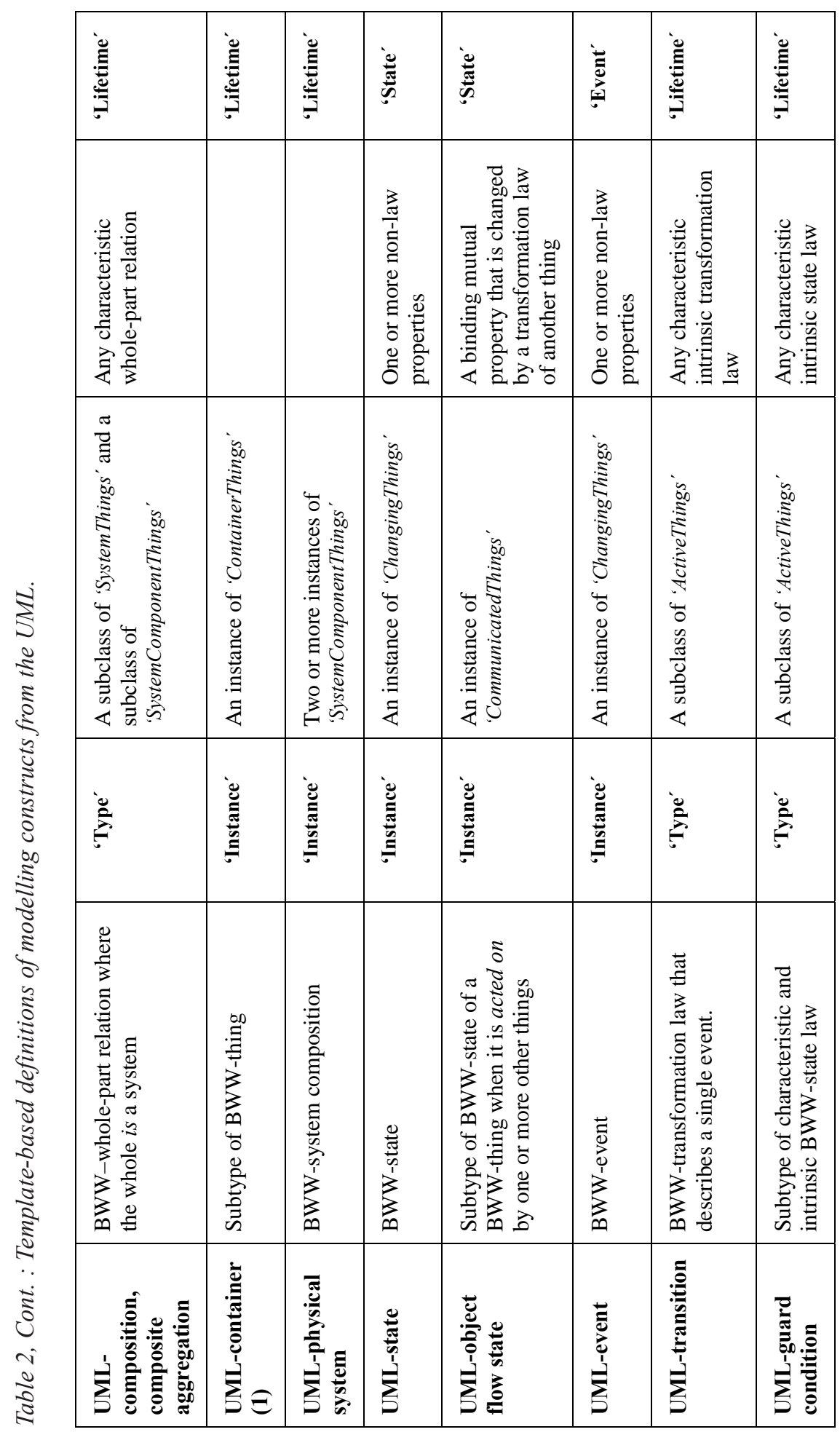




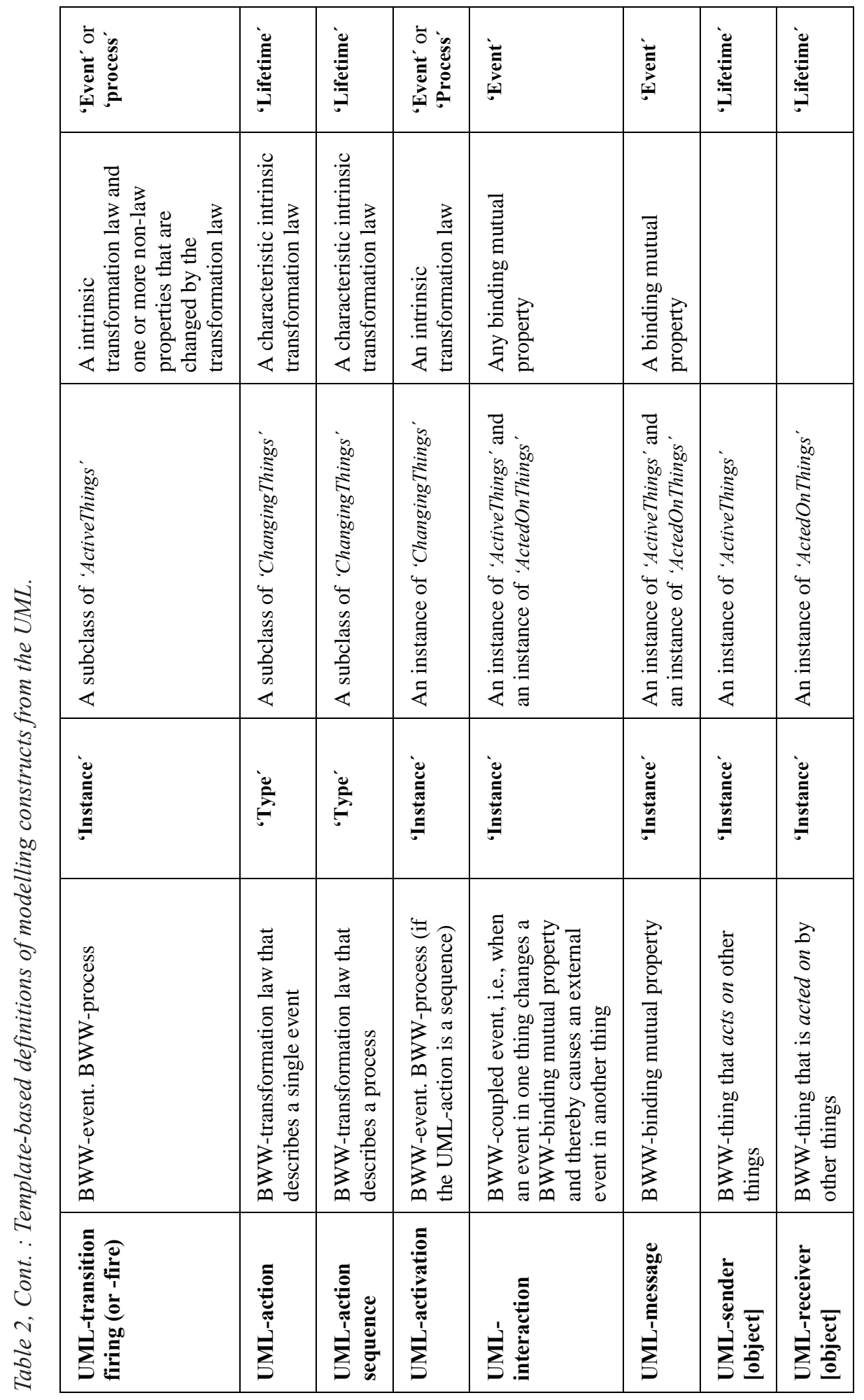




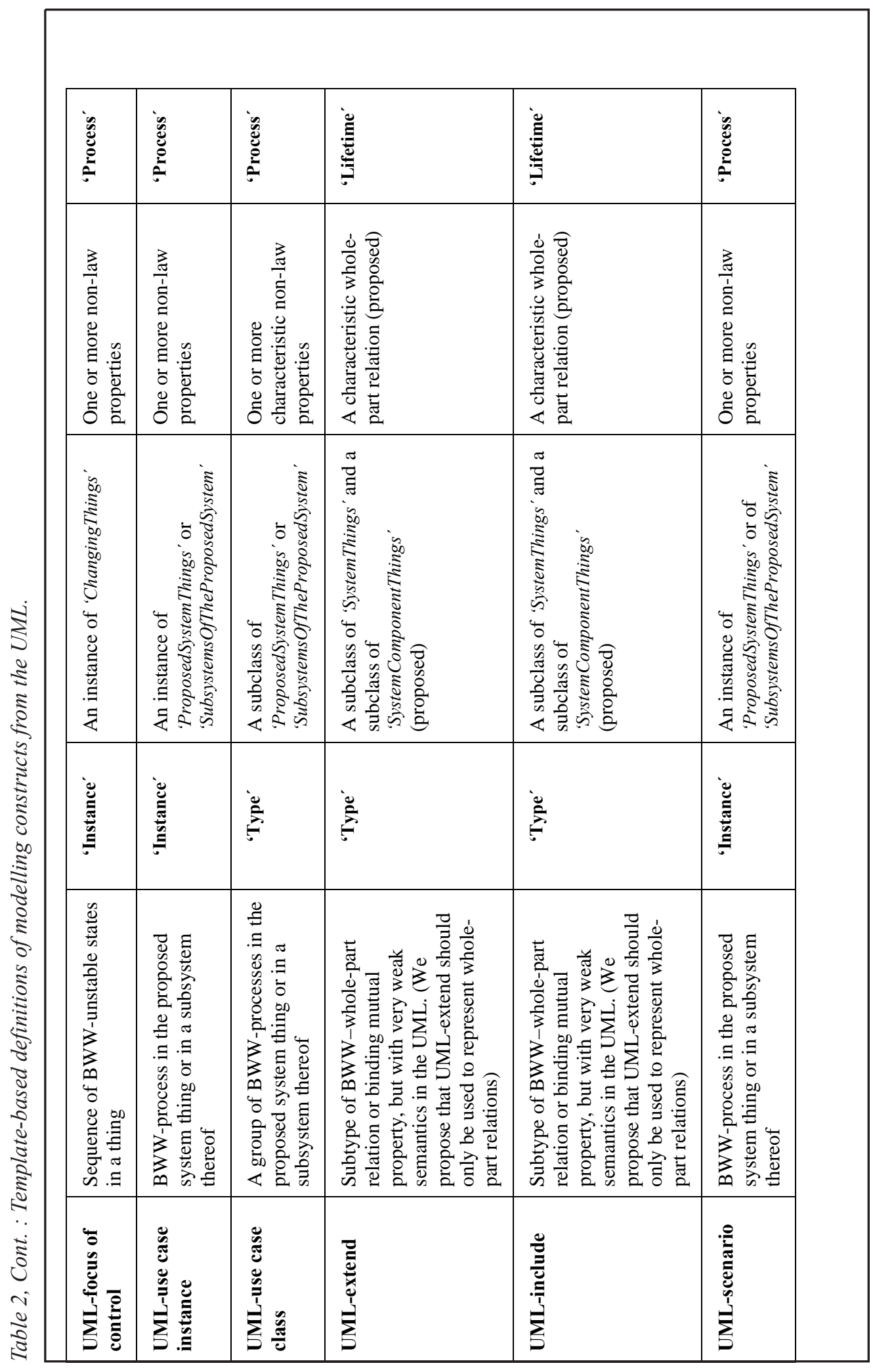




\begin{tabular}{|c|c|}
\hline :气 & 竞 \\
\hline 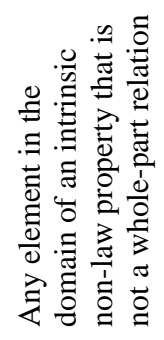 & 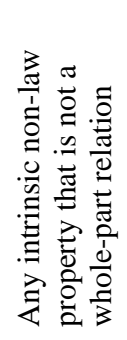 \\
\hline 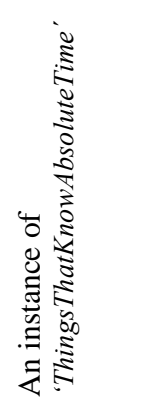 & 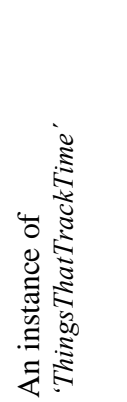 \\
\hline 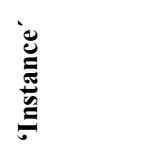 & 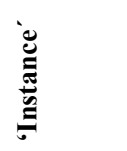 \\
\hline 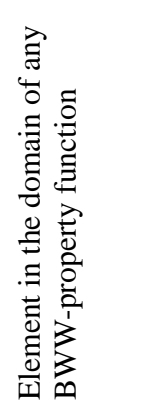 & $\begin{array}{l}\sum_{0}^{0} \\
0 \\
0 \\
0 \\
0 \\
0 \\
0 \\
0 \\
0 \\
0 \\
0 \\
0 \\
0 \\
0\end{array}$ \\
\hline 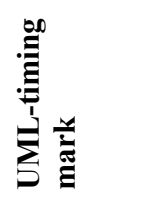 & 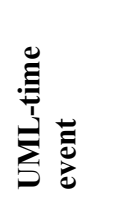 \\
\hline
\end{tabular}


Figure 3: The UML class diagram extended to show the property entry.

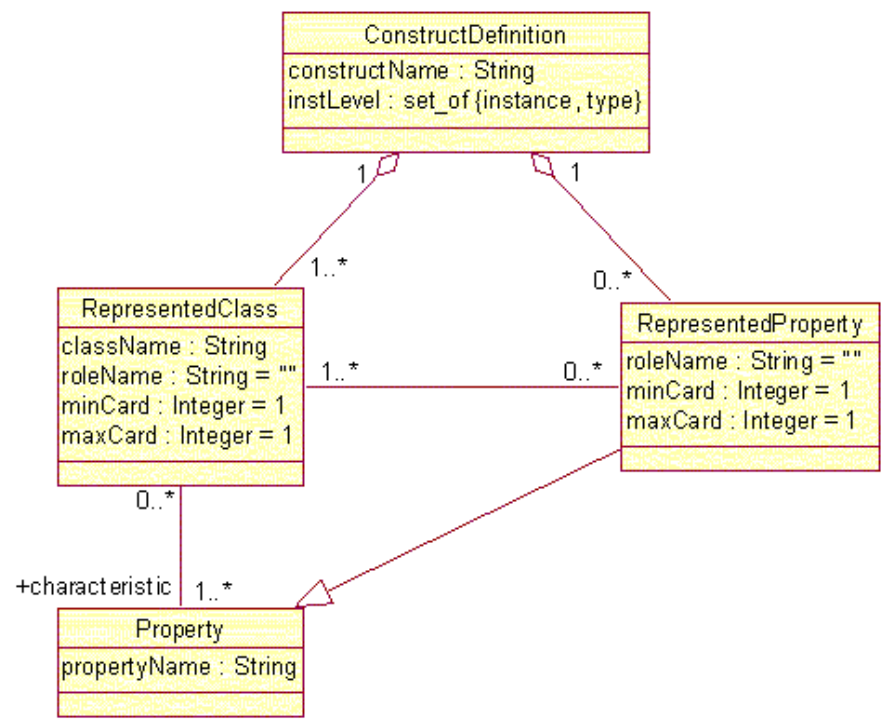

constructs that do so).

However, most modelling constructs have at least one property entry. In the languages we have studied, many of the property entries we encountered were not very restrictive and might represent any regular property, i.e., any intrinsic nonlaw BWW-property that is not a wholepart relation. We expect to find more examples of more restrictive property entries in less general, domain-specific modelling languages.

As for classes, the template allows repeated property entries for modelling constructs that may represent several characteristic properties of classes (at the type level) or several properties of things (at the instance level). Whenever a "ConstructDefinition" has more than one property entry, they must be distinguished by "roleNames", as shown in Figure 3. A "ConstructDefinition" may have more than one "RepresentedProperty" that specialises the same "Property", as long as they have different "roleNames".
Because the class entry may also be repeated, each "RepresentedProperty" is associated with one or more "RepresentedClass" to specify exactly to which class the property belongs in the definition.

Even when the property entry is not repeated, a modelling construct may represent the same property several times in the same role. In Figure 3, each "RepresentedProperty" therefore has a minimum and maximum cardinality, "minCard" and "maxCard" that default to 1 .

In the BWW model, a property may be mutual, i.e., it may belong to more than one thing. In the template, the corresponding "RepresentedProperty" would be associated with more than one "RepresentedClass". In fact, this was the case in several of the earlier examples. In the web application example, both "hyperlinks" and "target links" represented (different) mutual properties, each of them belonging to two "web-page" things, one playing the role of "source" and the other 
playing "target". In the UML-link example, UML-links represented a mutual property that belonged to two or more BWW-things. Finally, in the UML-aggregation example, the aggregation represented a property (the whole-part relation) that belonged both to the aggregate (whole) class and the component (part) class. The two "RepresentedClasses" used to define UML-aggregation, i.e., the "whole" and the "part" class, were therefore both linked to the same "RepresentedProperty" with "propertyName" "whole-part relation".

This concludes the discussion of property entries in the template. Together, the class and property entries form the core of the template. The two types of entries fit nicely with Bunge's view of the world as composed of things and properties, in terms of which the other BWW concepts are defined.

\section{Ontological Descriptions of Properties}

The BWW model has concepts that describe properties in even greater detail and that are also used in the template. Figure 4 extends the UML class diagram to show the additional attributes of "Properties" and

\section{"RepresentedProperties".}

Most importantly, according to the BWW model, a "RepresentedProperty" has an attribute that defines whether the modelling construct represents (a) the property per se, i.e., the BWW-property itself; (b) the property datatype, i.e., the BWW-property co-domain; (c) a property value, i.e., a value in the $\mathrm{BWW}$-property co-domain; or (d) some combination of these. For example, this attribute distinguishes between constructs like UML-attribute and -datatype, which are both at the type level and may represent any subclass of "AllThings" and any characteristic intrinsic property that is not a whole-part relation, because UMLattributes represent properties per se, whereas UML-datatypes of course represent datatypes. Accordingly, this attribute also distinguishes between UMLproperty and -value. UML-datatypes and -values are the only UML constructs we have encountered that represent property datatypes and values, but the attribute may be useful for languages with datatypes that can only be used in connection with certain modelling constructs. We have not found a use for identifying constructs that represent $B W W$-property functions explicitly, leaving this as a possible future extension.

A "Property" has an attribute that defines whether the modelling construct represents a non-law, a state law or a transition law according to the BWW model. For example, whereas a UMLattribute represents a non-law, a UMLoperation represents a law. A "Property" that is a law is described by an "oclExpression". A "Property" also has an attribute that defines whether the modelling construct represents a wholepart relation or not according to the BWW model. For example, whereas a UMLassociation cannot represent a whole-part relation, a UML-aggregation must do so.

Figure 4 also shows the additional attributes of the "ClassPropertyAssociation" class. The first of these defines whether the "RepresentedProperty" is intrinsic, nonbinding mutual or binding mutual with respect to a particular "RepresentedClass". To see why it is necessary to define this attribute in an association class, rather than in the “RepresentedProperty" class, consider the following hypothetical example. A 


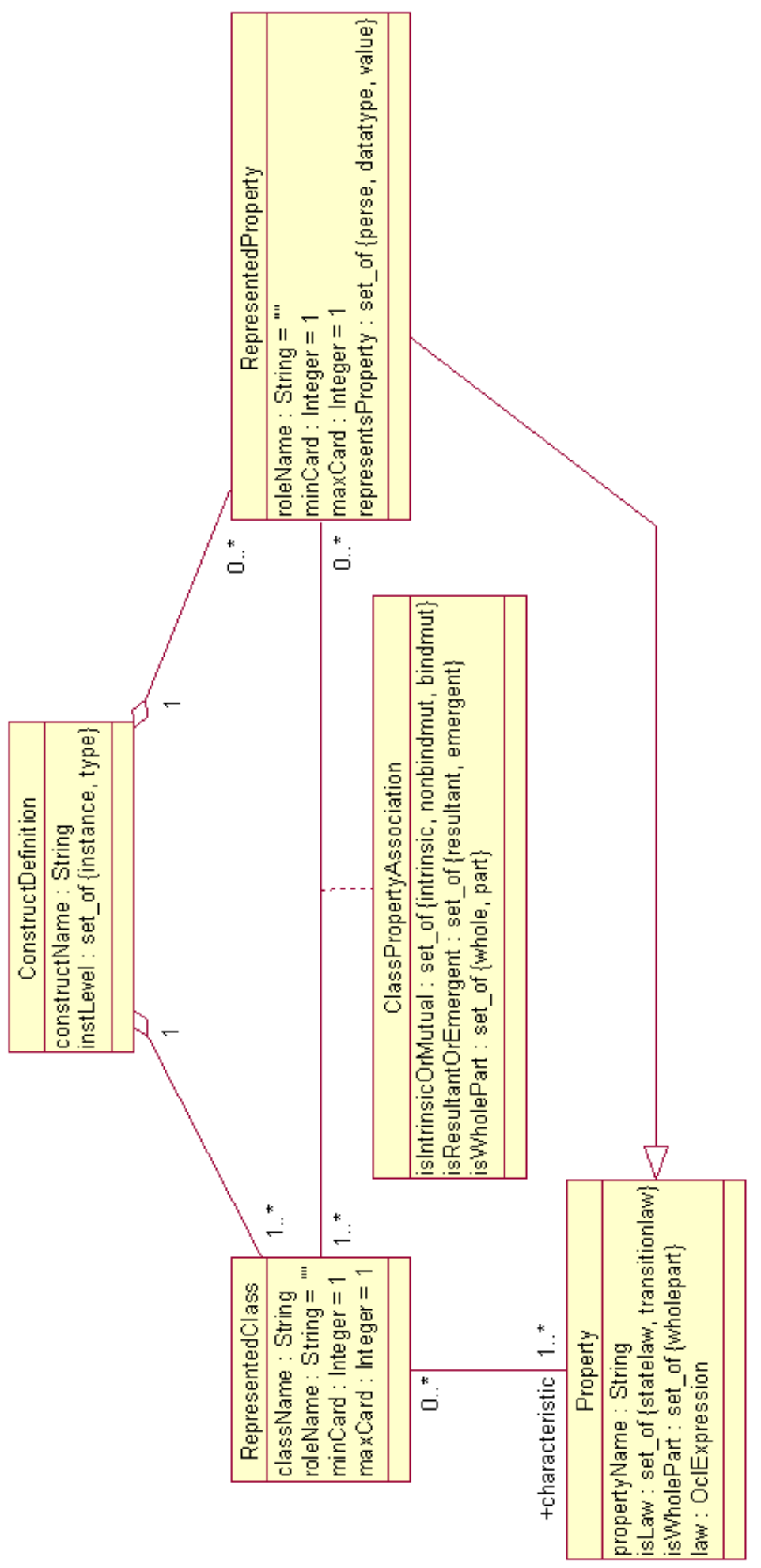


modelling construct represents a property that belongs to three things. Two of these things are parts of the third. The property is mutual between the two part things and is also a resultant property of the whole. In this case, the property is intrinsic with respect to the whole thing, but it is mutual with respect to the two part things. This explains why the "isIntrinsicOrMutual" attribute must be defined in an association class. Although the example is hypothetical, the situation it describes is not uncommon and it is not impossible that some modelling language may have a dedicated construct for it.

A “ClassPropertyAssociation" has another attribute that defines whether the "RepresentedProperty" is resultant, emergent or neither with respect to the “RepresentedClass". A final attribute applies only to "RepresentedProperties" that are whole-part relations and defines whether the "RepresentedClass" is the whole or the part in the relation or neither.

We need further experience with the template to determine how useful these ontologically motivated attributes of "Properties" and “ClassPropertyAssociations" are. Also, the template does not make use of Bunge's (1997) distinction between permanent and variable $\mathrm{BWW}$-properties, leaving this as a possible future extension.

\section{Lifetimes}

The fourth type of entry is used to define which part of the lifetime of a thing that the modelling construct may represent because, sometimes, different modelling constructs may represent the same class of things and the same properties of those things but different segments of the lifetimes of those things. For example, one construct may represent an event, another a state and a third a process, although all three constructs represent the same property of the same thing. This becomes obvious when we see that constructs that are as different as UML-state and UML-

Figure 5: The UML class diagram extended to show the lifetime entry.

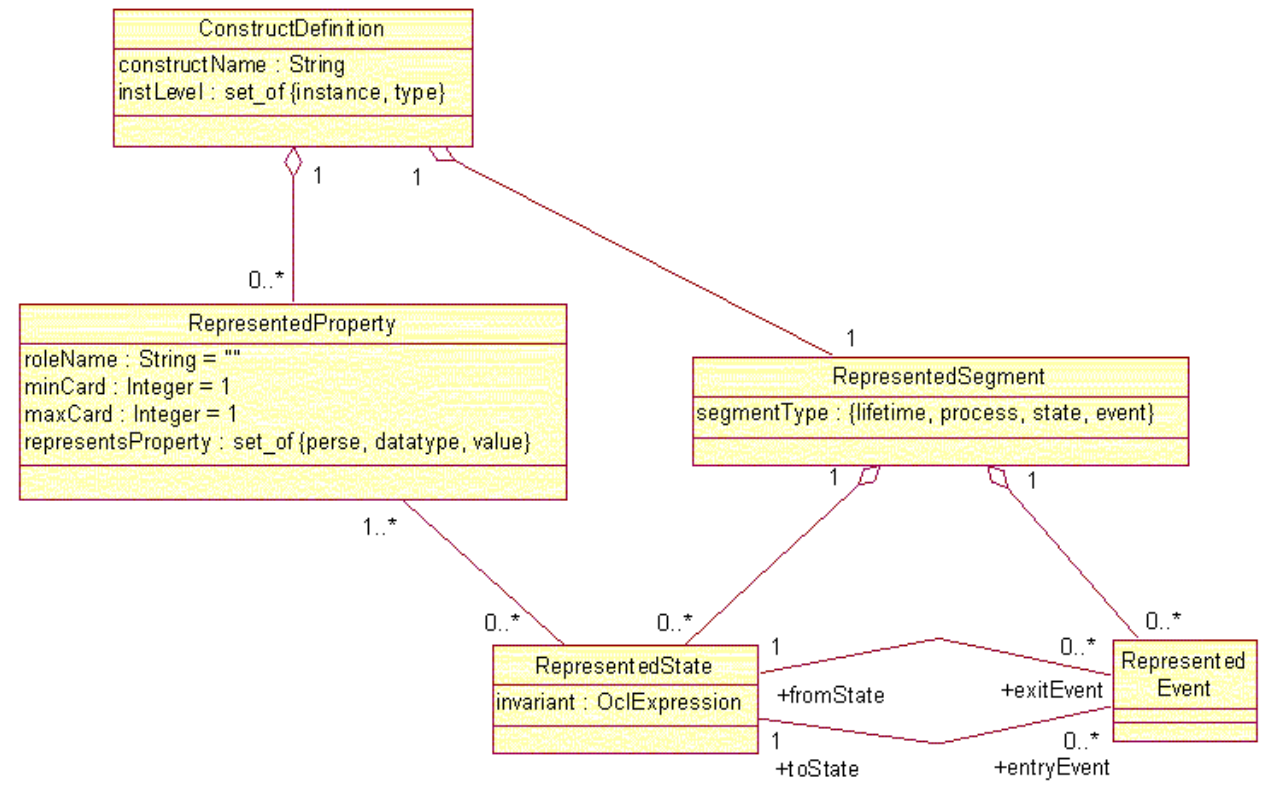


event have identical instantiation level, class and property entries. Both constructs represent the type level, may represent any subclass of the class of "ChangingThings" and may represent any non-law properties of those subclasses. However, they are distinguished by their lifetime entries.

Figure 5 extends the UML class diagram to show "RepresentedSegments" of the lifetimes of things and classes. A "ConstructDefinition" has exactly one "RepresentedSegment", which is either the whole "lifetime" of the thing or class, a "process", a "state" or an "event". "RepresentedSegments" that are "states" or "events" must also have a "RepresentedState" and/or a "RepresentedEvent" as parts. A "RepresentedState" is described by an "oclExpression" that involves “RepresentedProperties".

"RepresentedEvent" is defined in terms of its "from-" and "toStates". BWWprocesses are represented as chains of “RepresentedStates" and "-Events".

\section{Building Taxonomies}

As the template is used to define an increasing number of constructs from different modelling languages, the number of "RepresentedProperties" and "Properties" used to characterise "RepresentedClasses" will grow large. In this situation, it is essential that the same classes and properties are not represented independently several times using the template. Should this happen, the template would no longer aid in identifying modelling constructs that can be used to represent the same BWW-classes and -properties

The template should therefore be supported by a tool for defining modelling constructs, a tool that would also support building and maintaining a taxonomy of BWW-classes and -properties. Whenever a new modelling construct is defined using the template, this tool should provide overviews of the classes and properties that have been used in previous definitions so they can be reused. Whenever the new modelling construct necessitates defining new BWW-classes or -properties, they should be entered into the taxonomy.

Figure 6 extends the UML class diagram to show the taxonomy of "Classes" and "Properties" that can be reused in "ConstructDefinitions". Because "Classes" and "Properties" in the taxonomy are stored independently of "ConstructDefinitions", they are now connected to "RepresentedClasses" and “RepresentedProperties" via association rather than via generalisation/ specialisation.

In order to make the taxonomy more easy to use, both "Classes" and "RepresentedClasses" are organised in "generalisation" hierarchies, whereas "Properties" are organised through "precedence" relations and hierarchies of "complexProperties" and "subProperties", all according to the BWW model. A "propertySet" association is defined for "ConstructDefinitions" that may represent a choice of more than one "Property".

Figure 6 also shows that "States" and "Events" have been added to the taxonomy. Although less critical than classes and their properties, states and events also make the template easier to use, because the lifetime entries of new modelling constructs can sometimes be defined by reuse, and more useful, because the construct definitions become easier to compare. 


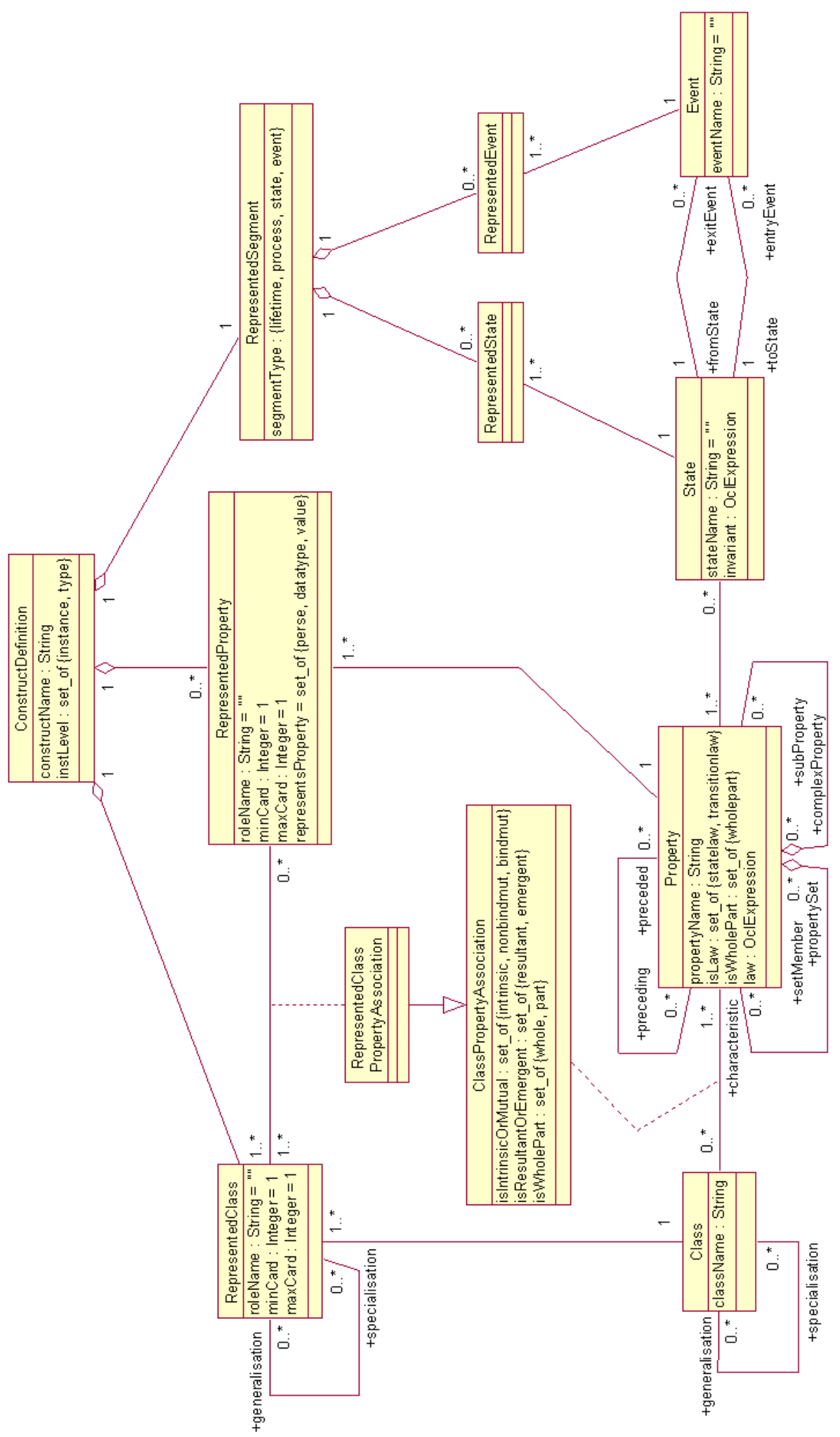




\section{RESULTS}

Modelling constructs from the Object Management Group's (OMG) standard Unified Modeling Language (UML) (OMG, 2001) were used in several examples so far. In part, the examples were based on experience from analysing the UML in terms of the BWW model in (Opdahl \& Henderson-Sellers, 2002) and from analysing a variant of UML, the OPEN Modelling Language (OML) (Firesmith, Henderson-Sellers \& Graham, 1997), in Opdahl, Henderson-Sellers and Barbier (1999) and Opdahl and HendersonSellers (2001). On the one hand, the UML is similar to the BWW model because it provides constructs that match key ontological concepts such as BWW-things (UML-objects), BWW-properties (many UML-features) and BWW-classes (UMLconcrete classes). ${ }^{3}$ On the other hand, a closer look at the UML definition in (OMG, 2001) reveals numerous problems, many of which are resolved by the template. This section will present results of using the template to define constructs from the UML. Of course, the most important result of using the template on the UML, that of integrating the UML with other modelling languages, cannot be illustrated at this stage of our work (because the UML is the first language we have presented results of analysing in this detail).

\section{The Generalisation Hierarchy of UML Constructs}

An important outcome of using the template on the UML is a generalisation hierarchy of BWW-classes that has emerged from the class entries for the UML constructs we have analysed, as shown in Figure 7. This hierarchy shows which BWW-classes in concrete problem domains are recognised by the UML. Each BWW-class in Figure 7 has been annotated with a list of those UML constructs that represent the class. The lists are based on the analysis by Opdahl \& HendersonSellers (2002), which interpreted 68 UML constructs that were relevant for representing concrete problem domains in terms of the BWW model. In this paper, 58 of these constructs have been defined using the template, as indicated in Table 2, although it is not the purpose of this paper to present our definitions in full detail. Ten UML constructs from Opdahl and Henderson-Sellers (2002) were left out because they, on closer inspection, turned out to be less relevant for modelling concrete problem domains or because they were subtypes of other constructs. ${ }^{4}$ Also, because the UML has weak semantics in relation to concrete problem domains today, many of the definitions are interpretations and proposals that must be evaluated in further work.

Generalisation hierarchies is a new and interesting approach to analysing, evaluating and comparing modelling languages. As a contribution to the analysis of the UML, Figure 7 shows clearly which types of model elements that may overlap with one another and may therefore be inconsistent. As a contribution to the evaluation of the UML, Figure 7 presents a generalisation hierarchy that is an alternative to the one in OMG (2001) and to which the UML metamodel may therefore be compared.

As pointed out by Opdahl \& Henderson-Sellers (2002), the modelling constructs in the UML have been defined to play several different roles, often at the same time, such as representing proposed software solutions, supporting the development process and matching with other modelling constructs to create a well- 


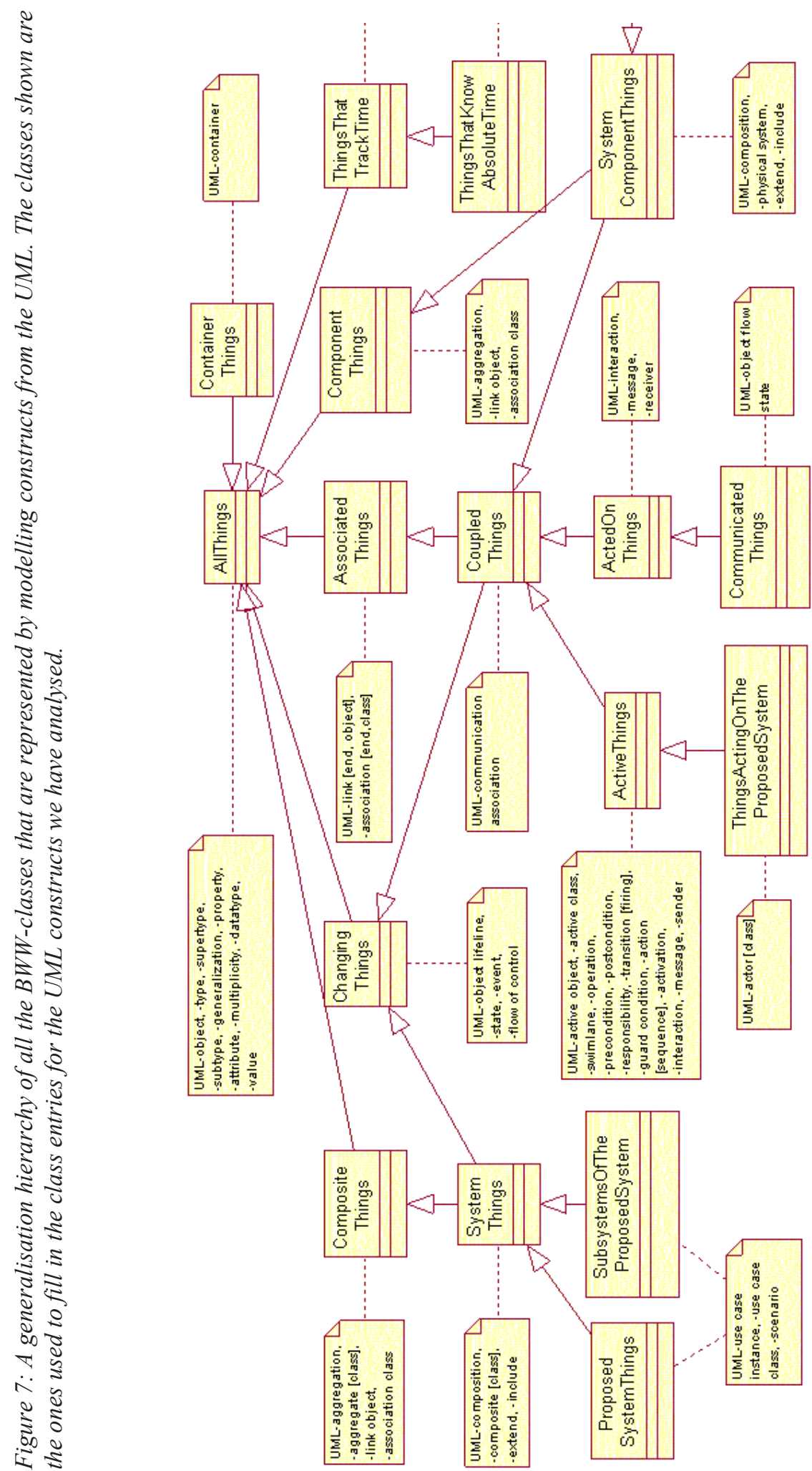


defined, compact and tightly integrated modelling language. This attempt to satisfy many different roles at the same time has made the generalisation hierarchies in the UML metamodel very hard to comprehend. Figure 7 offers a clear-cut alternative based on the constructs' semantics in relation to concrete problem domains. As a contribution to comparing modelling languages, we have already informally compared Figure 7 to generalisation hierarchies that have emerged from other languages we have analysed, such as the OML (Opdahl, Henderson-Sellers \& Barbier, 1999; Opdahl \& HendersonSellers, 2001). These hierarchies have many similarities and point towards a common generalisation hierarchy that can serve as a common ground for semantic language integration and which can be extended gradually as more languages are defined using the template. As in the BWW model, the generalisation hierarchy is likely to be a multi-inheritance graph rather than a single-inheritance tree.

\section{Precise Definitions of UML Constructs in Terms of Concrete Problem Domains}

Among the different roles mentioned in the previous section, we have found that UML constructs are often defined in terms of the proposed software system and not in terms of the problem domain (Wand \& Weber, 1989; Parsons \& Wand, 1997), i.e., the definition has given priority to the role of representing proposed software solutions over the role of representing the problem domain. For example, the UML glossary (OMG, 2001, appendix B) defines a UMLaction as "The specification of an [executable statement] that forms an abstraction of a [computational procedure.] An action typically results in a change in the state of the system, and can be realized by [sending a message] to an object or modifying a link or a value of an attribute." (The [brackets] and emphases are ours.) In this definition, the bracketed terms all refer to the proposed software solution and not to the problem domain. As with many constructs in the UML, the construct thereby becomes harder to use in practical modelling situations and the resulting models become less precise. Using the template, UML-action can be precisely defined in terms of concrete problem domains, as representing the type level, the class of "ChangingThings", any property that is a characteristic and intrinsic BWW-transformation law that describes a single event and the lifetime of the "ChangingThings". (It describes the lifetime because the things possess the transformation law for as long as they exist, even though the law itself only describes an event.)

In the above definition, there are even emphasised terms that all support the development process and do not refer to the problem domain. Definitions that mix software, development and problem domain issues are confusing and detrimental to the learnability and usability of the language. Mixed definitions also weaken the semantics of the language, because when unrelated terms are mixed in the same definition, the result is several incomplete definitions instead of a single coherent one. For example, a UML-object is defined using a mixture of software (our [brackets]) and problem domain (our $\{$ braces $\}$ ) issues as "An [ entity $\}]$ with a well—defined \{boundary\} and [identity] that [encapsulates] [ $\{$ state $\}]$ and [\{behavior $\}] . "$ This definition is incoherent, because it is not at all clear what a "welldefined boundary" or the concept of "encapsulation" (at least in the likely interpretation of it as meaning information 
hiding) mean in relation to concrete problem domains. Again, this problem is avoided using the template, according to which UML-object is precisely defined as representing the instance level, the class of “AllThings", not representing properties of those things but representing their whole lifetimes.

For another example, the glossary defines UML-reception as a "declaration that a classifier is prepared to react to the receipt of a signal", but it is unclear whether this "declaration" is static or dynamic, because "declaration" is left undefined. The template would have avoided this ambiguity, because the lifetime entry explicitly requests this to be defined.

Finally, using the template helps avoiding circular definitions, which Castellani (1998) demonstrates to be common in the UML, because each construct definition involves only filling in the standard set of entries, and none of the entries allow references to other construct definitions. The instantiation level, ontological and lifetime entries are all specified in terms of a limited number of attributes with a limited set of possible values for each. Circularities cannot occur in class entries either, because "Classes" are defined only in terms of "Properties" and never refer to other "Classes". The only place where circularities can potentially occur is therefore in property entries, where "Properties" may refer to other "Properties" through precedence relations. However, precedence circularities can easily be avoided by manual checking or by simple tool support.

\section{DISCUSSION}

The main idea behind the template was to provide a standard way of defining enterprise and IS modelling constructs in terms of the BWW model, in order to make the definitions cohesive and, thus, learnable, understandable and as directly comparable to one another as possible. When all construct definitions are directly comparable, it becomes easier to translate models from one language to another. It also becomes easier to detect models and model elements, possibly expressed in different languages, that may overlap with one another and may therefore be inconsistent. Another important idea was to provide a way of defining modelling constructs not only generally in terms of whether they represent "classes", "properties" or other ontological concepts, but also in terms of which classes and/or properties they represent. As we have seen, this additional level of detail was necessary to differentiate important modelling constructs in the UML. The additional level of detail also made the definitions more clearly and precisely related to the enterprise.

Clearly and precisely defined modelling constructs better support several of the quality features discussed in Lindland, Sindre and Sølvberg (1994) and Krogstie, Lindland and Sindre (1995), and languages become easier to learn, comprehend and use. Also, semantic overlaps (Spanoudakis \& Finkelstein, 1998, 1999) (or construct redundancies (Wand \& Weber, 1993)) and semantic omissions in languages (or construct deficits (Wand \& Weber, 1993)) can be detected more easily and more precisely, along with redundant constructs, i.e., constructs that do not refer to anything in the problem domain. At the model level, inconsistencies, conflicts and omissions in models can be detected more easily and precisely. There is also less scope for misunderstanding of the resulting requirements. 
The template supplements other contributions that make the BWW model more precise and useful: 1) Wand and Weber (1995) have provided a tabular description of the main concepts in their model, from which Table 1 in this paper was derived. 2) Wand and Weber (1990) have also provided a set-theoretic formulation of the BWW model. 3) Recently, Rosemann and Green (2002) have proposed an extended ER model of the main concepts in the BWW model. These contributions each make the BWW model more precise, but they do not 1) provide an obvious standard way of defining modelling constructs so that different definitions are directly comparable, nor do they 2) provide a way of saying that a modelling construct represents, e.g., a specific class or a specific property.

The template has been illustrated with definitions of constructs from the UML and, thereby, also supplements other contributions that use the BWW model to analyse the UML. Evermann and Wand (2001) present ontology-based rules for using the UML to model the real world, whereas Opdahl \& Henderson-Sellers (2002) use the BWW model to analyse and evaluate the UML as a language for representing concrete problem domains. However, in contrast to this paper, neither contribution addresses in detail the question of how to define modelling constructs in relation to the BWW model.

\section{CONCLUSIONS AND FURTHER WORK}

The paper has explained the need for a standard way of defining modelling constructs from different enterprise modelling languages and has proposed a template for defining enterprise modelling constructs in a way that facilitates language integration. The template was based on the Bunge-Wand-Weber

(BWW) representation model of information systems (IS) — called just the BWW model in this paper-and was illustrated with definitions of constructs from the Unified Modeling Language (UML). The paper focussed on modelling constructs that represent concrete problem domains, i.e., on representation of materials rather than concepts. The main idea behind the paper was to provide a standard way of defining modelling constructs in terms of the BWW model, in order to make the definitions cohesive and, thus, learnable, understandable and as directly comparable to one another as possible. Another important idea was to provide a way of defining modelling constructs not only generally, in terms of whether they represent "classes", "properties" or other ontological categories, but also in terms of which classes and/or properties they represent, in order to make the definitions more clearly and precisely related to the enterprise. Although most of the paper was about the concrete parts and aspects of enterprises, we believe the template and other results of this paper are sufficiently general to apply to concrete problem domains in general.

An important outcome is that the template encourages thorough analyses and precise definitions of enterprise, IS and other problem domain modelling constructs and languages. In particular, it assists in identifying semantical overlaps (Spanoudakis \& Finkelstein, 1998, 1999) at a detailed level between seemingly unrelated modelling constructs and their languages. The template is also useful for identifying constructs that are too complex or too vaguely defined. Thereby, the 
template paves the way both for more precise and tightly integrated enterprise and IS models and for better completeness and consistency checking of models. However, we do not mean to imply that all enterprise and IS modelling languages and all models should necessarily be integrated or even defined in terms of a standard template. In many situations, e.g., to foster creativity when a new opportunity is identified or a new IS is to be conceptualised, there will be a need for modelling languages and constructs that challenge the commonly accepted ground. The important issue is that problem domain modelling languages that are integrated and defined in terms of a standard template should be available when they are called for. Also, we do not mean to imply that all enterprise and IS modelling languages and models should necessarily be as precisely defined as possible. Whereas in some situations, models (and thus languages) should be precise, other situations might call for less precise models and languages, e.g., to represent early ideas of the problem domain during initial development. Again, the important issue is that problem domain modelling languages should support precise modelling when this is called for. Further work is needed to investigate how to define languages that provide more and less precise semantics for different stages of development.

Another important outcome is the identification of the generalisation hierarchy that is inherent in the UML. This type of generalisation hierarchy is a new way of analysing and comparing modelling languages and constructs. It offers both a new way to clarify and explain the semantics of the UML and introduces a new perspective from which the UML can be constructively criticised.

The template demonstrates again the applicability and usefulness of the BWW model as the foundation for work that addresses the semantics of enterprise and IS modelling languages. The template also makes the BWW model more applicable and useful in practice. Rosemann and Green (2002) point out that although the BWW model has produced important research results, it is large and complex and therefore difficult to learn and use. The template makes the BWW model simpler to use by decomposing construct definitions into five entries that are largely independent and that each are simpler than the BWW model or the template as a whole. At the same time, the template does not deviate much from the BWW model. Although at first sight, the template does not account for all the BWW-concepts presented in other papers (e.g., Wand \& Weber, 1988, 1993, 1995), it accounts for all the basic ones, so that modelling constructs defined in terms of the template should also be implicitly related to the rest of the BWW model. However, this needs to be verified in further work.

Further work is needed to validate and refine the proposal made here, both by relating the template to other ontologies and other mathematical formalisms and by using it on additional modelling languages and constructs. For example, it would be interesting to use the template to define the constructs in the ARIS language (Green \& Rosemann, 1999) for business process modelling and to define intentional modelling constructs such as goals and speech acts. The current version of the metamodel has been developed to be clear and understandable but, especially when it comes to the ontological descriptions of properties, it has some redundancies that need to be sorted out.

Further work is also needed on tool support for the template. Such a tool would 
assist definition of modelling constructs in terms of the five types of entries and would manage dependencies between entries. If would also assist in maintaining the taxonomy of "Classes", "Properties", "States" and "Events". The tool could also support analysis of modelling languages, e.g., by automatically generating generalisation hierarchies and identifying overlapping modelling constructs.

The template presented in this paper focusses on modelling constructs that represent concrete problem domains, i.e., that represent materials rather than concepts. Further work should extend the template to account for modelling constructs that represent social constructs and mental concepts. Also, as pointed out by Opdahl and Henderson-Sellers (2002), representing problem domains - be they material, social or mental-is only one of several roles played by enterprise and IS modelling constructs, which must also sometimes represent proposed software solutions, support modellers and software developers ,and match other modelling constructs to create a well-defined, compact and tightly integrated modelling language. The current version of the template only deals with material problem domains and offers little help with managing these additional roles.

\section{ACKNOWLEDGMENTS}

This is Contribution number $02 / 17$ of the Centre for Object Technology Applications and Research.

\section{ENDNOTES}

1 Following an observation made by Opdahl and Henderson-Sellers (2002), UML-class is not prominent in this paper because UML-type, a stereotype of UML-class in UML Version 1.4, is more specific to representing concrete problem domains like enterprises.

2 Here, we make a distinction between general ontology, such as the BWW model, and special or domain-specific ontology, which is a high-level, generic and often reusable model of a problem domain. Bunge (1999) makes a similar distinction between general ontology, which "studies all existents", and special ontology, which "studies one genus of thing or process."

3 Table 2 in Opdahl and HendersonSellers (2002) gives a full list of 14 ontological matches or near matches between the UML and the BWW model, whereas Opdahl and Henderson-Sellers (2001) summarise key ontological differences between OO-modelling in general and the BWW model.

4 The 10 constructs left out were UMLclass (because UML-types are more relevant, see footnote 1), UML-send and -receive, UML-action, -call, -subactivity, -synch and -final state and UML-signal and-stimulus.

\section{REFERENCES}

Barbier, F., Henderson-Sellers, B., Opdahl, A.L. \& Gogolla, M. (2000). The whole-part relationship in the Unified Modeling Language: A new approach. In Halpin, T. \& Siau, K. (eds.), Unified Modeling Language: Systems Analysis, Design, and Development Issues. Hershey PA: Idea Group Publishing (IGP).

Bodart, F., Patel, A., Sim, M. \& Weber, R. (2001). Should optional properties be used in conceptual modelling? A theory and three empirical tests. Information Systems Resear ch, 12(4), 384-405. 
Bunge, M. (1977). Treatise on Basic Philosophy: Vol. 3: Ontology I: The Furniture of the $W$ orld. Boston:Reidel.

Bunge, M. (1979). Treatise on Basic Philosophy: Vol. 4: Ontology II: A World of Systems. Boston:Reidel.

Bunge, M. (1999). Dictionary of Philosophy. Amherst:Prometheus Books.

Castellani, X. (1998). An overview of the version 1.1 of the UML defined with charts of concepts. In P.A. Muller and Bézivin, J. (eds.), Proc. "International Conference on the Unified Modeling Language, $<<U M L>>$ '98 - Beyond the Notation", Mulhouse/France, June 3.4. LNCS, Springer Verlag.

Chisholm, R.M. (1996). A Realistic Theory of Categories: An Essay on Ontology. Cambridge University Press.

Conallen, J. (1999). Modeling Web Application Architectures with UML. Communications of the ACM , 42(10). (Special Issue on UML, Booch, G. (guest ed.))

Evermann, J. \& Wand, Y. (2001). Towards ontologically based semantics for UML constructs. In Kunii, H., Jajodia, S. \& Solvberg, A. (eds.), Proc. "20th International Conference on Conceptual Modeling”, ER 2001, Yokohama, Japan, Nov. 27-30, 2001.

Firesmith, D., Henderson-Sellers, B. \& Graham, I. (1997). OPEN Modelling Language - OML Refer ence Manual. SIGS Books. Cambridge University Press.

Green, P.F. (1996). An Ontological Analysis of Information Systems Analysis and Design (ISAD) Grammars in Upper CASE Tools. PhD thesis, Department of Commerce, University of Queensland.

Green, P. \& Rosemann, M. (1999). An ontological evaluation of integrated process modelling. In Proceedings "11th Conference on Advanced Information Systems Engineering”, CAiSE*99,
Heidelberg/Germany, 14-18 June 1999. Springer.

Green, P. \& Rosemann, M. (2000). Integrated process modelling: An ontological evaluation. Information Systems, 25(2), 73-87.

Krogstie, J., Lindland, O.I. \& Sindre, G. (1995). Towards a deeper understanding of quality in requirements engineering. In Iivari, J., Lyytinen, K. \& Rossi, M. (eds.), Advanced Information Systems Engineering, $\mathrm{Pr}$ oc. CAiSE*95, Jyväskylä. LNCS 932, Springer Verlag.

Lindland, O.I., Sindre, G. \& Sølvberg, A. (1994). Understanding quality in conceptual modeling. IEEE Software, 11(2):42-49, March.

OMG (2001). OMG Unified Modeling Language Specification, version 1.4. Object Management Group.

Opdahl, A.L., Henderson-Sellers, B. \& Barbier, F. (1999). An ontological evaluation of the OML metamodel. In Falkenberg, E.D., Lyytinen, K. \& VerrijnStuart, A.A. (eds.), Information System Concepts: An Integrated Discipline Emerging, pp. 217-232. Kluwer (IFIP 8.1).

Opdahl, A.L., Henderson-Sellers, B. \& Barbier, F. (2001). Ontological analysis of whole-part relationships in OO models. Information and Softwar e Technology, 43(6), 387-399.

Opdahl, A.L. \& Henderson-Sellers, B. (2001). Grounding the OML metamodel in ontology. Journal of Systems and Software, 57(2), 119-143.

Opdahl, A.L. \& Henderson-Sellers, B. (2002). Understanding and improving the UML metamodel through ontological analysis. Journal of Softwar $e$ and Systems Modelling (SoSyM), 1(1):43-67, Springer.

Parsons, J. \& Wand, Y. (1997). Using objects for systems analysis. Communications of the ACM , 40(12), 
104-110.

Parsons, J. \& Wand, Y. (2000). Emancipating instances from the tyranny of classes in information modeling. ACM Transactions on Database Systems, 25(2), 228-268.

Paulson, D. \& Wand, Y. (1992). An automated approach to information systems decomposition. IEEE Transactions on Software Engineering (TSE), 18(3), 174189.

Rosemann, M. \& Green, P. (2002). Developing a meta model for the BungeWand-Weber ontological constructs. Information Systems, 27, 75-91.

Spanoudakis, G., Finkelstein, A. \& Till, D. (1999). Overlaps in requirements engineering. Automated Softwar $e$ Engineering Journal .

Spanoudakis, G. \& Finkelstein, A. (1998). A semi-automatic process of identifying overlaps and inconsistencies between requirement specifications. In Proc. "5th International Confer ence on Object-Oriented Information Systems", OOIS 98, 405-424.

Takagaki, K. \& Wand, Y. (1991). An object-oriented information systems model based on ontology. In Van Assche, F., Moulin, B. \& Rolland, C. (eds.), Object Oriented Appr oach in Information Systems, pp. 275-296, Amsterdam:Elsevier (North-Holland).

Uschold, M., King, M., Moralee, S. \& Zorgios, Y. (1998). The enterprise ontology. The Knowledge Engineering Review, 13.

Verrijn-Stuart, A.A. (ed.) (2001). A Framework of Information System Concepts - The Revised FRISCO Report. Web document, draft version.

Wand, Y. \& Wang, R.Y. (1996). Anchoring data quality dimensions in ontological foundations. Communications of the ACM, 39(11), 86-95.
Wand, Y. \& Weber, R. (1988). An ontological analysis of some fundamental information systems concepts. In DeGross, J.I. \& Olson, M.H. (eds.), Proceedings of the Ninth International Confer ence on Information Systems, Minneapolis/ USA, November 30-December 3, 1988,213-225.

Wand, Y. \& Weber, R. (1989). An ontological evaluation of systems analysis and design methods. In Falkenberg, E. \& Lindgreen, P. (eds.), Proceedings of the IFIP WG8.1 Working Conference on "Information Systems Concepts: An InDepth Analysis”, Namur, Belgium, pp. 79-107, Amsterdam:North-Holland.

Wand, Y. \& Weber, R. (1990). An ontological model of an information system. IEEE $T$ ransactions on Softwar $e$ Engineering (TSE), 16(11), 1282-1292.

Wand, Y. \& Weber, R. (1993). On the ontological expressiveness of information systems analysis and design grammars. Journal of Information Systems, 3:217-237.

Wand, Y. \& Weber, R. (1995). On the deep structure of information systems. Information Systems Journal, 5, 203-223.

Wand, Y. (1989a). An ontological foundation for information systems design theory. In Pernici, B. \& Verrijn-Stuart, A.A. (eds.), Office Information Systems: The Design Process. Amsterdam:Elsevier (North-Holland).

Wand, Y. (1989b). A proposal for a formal model of objects. In Kim, W. \& Lochovsky, F.H. (eds.), Object-Oriented Concepts, Databases, and Applications , chapter 21, pages 537-559. New York:ACM Press/Addison-Wesley.

Weber, R. \& Zhang, Y. (1996). An analytical evaluation of NIAM's grammar for conceptual schema diagrams. Information Systems Journal, 6:147-170. Weber, R. (1997). Ontological 
Foundations of Information Systems . Number 4 in Accounting Research Methodology Monograph series. Coopers
\& Lybrand, 333 Collins Street, Melbourne Vic 3000, Australia.

Andreas L. Opdahl is Pr ofessor of Information Systems Development in the Department of Information Science, University of Ber gen, Norway. Dr. Opdahl is the author, co-author or co-editor of mor e than 30 journal ar ticles, book chapters, refereed archival conference papers and books on $r$ equirements engineering, multiperspective enterprise modelling, softwar e performance engineering and other areas. He is a member of IFIP WG8.1 on Design and Evaluation of Information Systems. He ser ves regularly as a r eviewer for pr emier international journals and on the program committees of $r$ enowned international confer ences and workshops. Opdahl can be contacted at postal addr ess: Depar tment of Information Science, University of Ber gen, P.O.Box 7800,N-5020 Ber gen, Norway, andreas@ifi.uib.no, http://www.ifi.uib.no/staff/andreas/.

Brian Henderson-Sellers is Dir ector of the Centr e for Object T echnology Applications and Resear ch and Pr ofessor of Information Systems at University of Technology, Sydney (UTS). He is author of eleven books on object technology and is well-known for his work in OO methodologies (MOSES, COMMA, OPEN, OOSPICE) and in OO metrics. Brian has been Regional Editor of Object-Oriented Systems, a member of the editorial boar d of Object Magazine/Component Strategies and Object Expert for many years and is curr ently on the editorial board of Journal of Object Technology and Softwar e and Systems Modelling. He was the Founder of the Object-Oriented Special Inter est Group of the Australian Computer Society (NSW Branch) and Chairman of the Computerworld Object Developers' A wards committee for ObjectW orld 94 and 95 (Sydney). He is a fr equent, invited speaker at international OT confer ences. In 1999, he was voted number 3 in the Who' $s$ Who of Object T echnology (Handbook of Object T echnology, CRC Press, Appendix $N)$. He is curr ently a member of the $r$ eview panel for the OMG's Software Process Engineering Model (SPEM) standar ds initiative and is a member of the UML 2.0 review team. In July 2001, Pr ofessor Henderson-Sellers was awar ded a Doctor of Science (DSc) fr om the University of London for his $r$ esearch contributions in object-oriented methodologies 